\title{
Genetic algorithms in supply chain management: A critical analysis of the literature
}

\author{
SUNIL KUMAR JAUHAR* and MILLIE PANT \\ Department of Applied Science and Engineering, Indian Institute of Technology Roorkee, Roorkee 247667, \\ India \\ e-mail: suniljauhar.iitr@gmail.com; millidma@gmail.com
}

MS received 29 February 2016; revised 30 March 2016; accepted 5 April 2016

\begin{abstract}
Genetic algorithms (GAs) are perhaps the oldest and most frequently used search techniques for dealing with complex and intricate real-life problems that are otherwise difficult to solve by the traditional methods. The present article provides an extensive literature review of the application of GA on supply chain management (SCM). SCM consists of several intricate processes and each process is equally important for maintaining a successful supply chain. In this paper, eight processes (where each process has a set of subprocesses) as given by Council of SCM Professionals (CSCMF) are considered. The idea is to review the application of GA on these aspects and to provide the readers a detailed study in this area. The authors have considered more than 220 papers covering a span of nearly two decades for this study. The analysis is shown in detail with the help of graphs and tables. It is expected that such an extensive study will encourage and motivate the fellow researchers working in related area; to identify the gaps and to come up with innovative ideas.
\end{abstract}

Keywords. Genetic algorithms; supply chain management; inventory management; soft computing.

\section{Introduction}

Maintaining an efficient supply chain has always been a focus of attention of scientists and researchers since decades. In fact, the entire economy of a country more or less depends on an efficient and well-managed supply chain processes. However, with the growing competition all round the world; the SCM models are also becoming more complex day by day. Consequently, researchers are focusing on efficient and robust techniques for dealing with SCM. In this article, a review on the application of GA, one of the most popular techniques, for dealing with different aspects of SCM is presented. The popularity of GAs for solution of SCM can be attributed to its capability to evolve solutions, handle ambiguity, and execute optimization [1]; its competence to tolerate imprecision, uncertainty, and partial truth to attain tractability and robustness on simulating human decisionmaking behavior with low cost [2, 3].

Moreover, GA has been applied quite successfully to a wide range of problems occurring in diverse SCM domains, for example, forecasting [4], job-shop scheduling [5], economic lot-size scheduling [6], economic lot-size model [7], vendor-managed replenishment system [8]. Therefore, it is quite natural to assume that for SCM processes and sub-processes, GA has always been an option for dealing with SCM models.

*For correspondence
The present study is an extension of paper presented by authors [9] that focuses on GA applications to SCM. Here the authors have provided a much more detailed analysis including figures, charts, and graphs. The articles reviewed for this study cover almost two decades; from the late 1990s until the present time. Through this review the reader can easily visualize how GA has evolved for solving the different aspects of SCM.

The rest of the research article is prepared as follows: Subsequent to the introduction in section 1, the genetic algorithms and supply chain management are briefly described in sections 2 and 3 respectively. The methodology, section 4 , describes the critical analysis of the literature and reviews of existing studies and section 5 briefed discussion part and future trends of the study. Finally, Summary drawn from the present study is provided in the last section 6 .

\section{Genetic algorithms}

GA is an evolutionary algorithm first proposed by John Holland and his colleagues in 1975. Based on Darwin's theory of survival of the fittest, it is one of the most popular search technique used for solving optimization problems. It is a derivative free, direct search algorithm used to find true or approximate solutions to optimization and search problems [10]. Some pioneering work in GA can be found in 


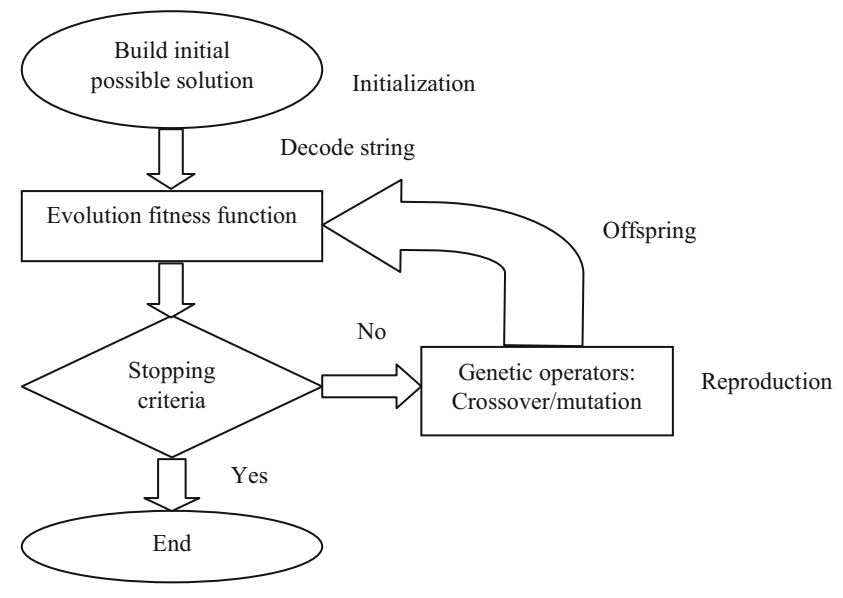

Figure 1. Interconnection of GA stages.

[11-19]. The working of GA begins by initialization of the population of $n$ chromosomes within the given range. The second step is to decide a fitness function that helps in assessing the fitness of every single chromosome in the population. After this phase, GA operators (crossover plus mutation) are activated, which help in generating the new population. The procedure is repeated iteratively till a stopping criterion is met. An interconnection of GA phases is shown in figure 1 .

\subsection{Computational steps of GA}

(1) Build initial population of randomly generated solutions.

(2) Evaluation of the fitness function of individual solutions in the population.

(3) Generate new population by repetition of subsequent phases as follows:

- Selection: Pick a pair of parent solutions from a population corresponding to their fitness. The one having a superior fitness value is more likely to be selected.

- Crossover: Perform crossover with the help of a predefined crossover probability to produce new child solution.

- Mutation: Perform mutation by means of a predefined mutation probability.

(4) Adopt newly build population for an additional run of the algorithm.

(5) Check whether the stopping criterion has been reached. If yes, then terminate; otherwise go to step 2.

Several variants of GA are available in literature, including binary and real encoded; unconstrained and constrained; and single objective and multiobjective, depending on the type of problem being dealt with, the suitable variant may be applied.

\section{Supply chain management}

SCM is a set of approaches of managing upstream and downstream interrelationship with suppliers and its clients to deliver high-quality customer value at lowest possible price as a whole supply chain [20,21]. Its aim is to manufacture as well as allocate the products and services in the right amount, to the right location, also at the right time so as to reduce cost while retaining customer satisfaction [4], figure 2 shows the SCM linkages.

\section{Methodology}

In the present study, 220 articles are considered where GA has been applied for dealing with different aspects of SCM. The authors have mainly concentrated on refereed articles. The main keywords; "Genetic algorithms" and "Supply chain management" are searched for in major databases. The other keywords include the GAs applications to SCM process and sub-processes "Inventory Management, Material Planning", "Supply Chain Planning, Production Planning", "Logistics Network Design/Planning, Vehicle Routing/Assignment", "Sales Forecasting, Bullwhip Effect", "Supplier relationship management", "Product development and commercialization", "Returns management", "Customer service management", and "Customer relationship management". The papers are segregated as per the area, and analysis is done to find out where and how GAs are applied. Graphs and charts are drawn so that the reader can easily visualize in which areas of SCM have GAs been used most frequently and in which areas some more work is to be done.

The present study is inspired by [22], main difference being that in the present paper the authors have focused on GA, while in [22], besides GA, the soft computing approaches such as fuzzy logic and neural network are also considered. The main similarity between [22] and the present study is that in both the studies eight processes of SCM as given by Council of SCM Professionals (CSCMF) are considered. These processes are given as follows:

\subsection{Manufacturing flow management (MFM)}

4.1a Inventory management/material planning

4.1b Supply chain planning

4.1c Production planning

\subsection{Order fulfillment (OF)}

4.2a Logistics network design/planning

$4.2 \mathrm{~b}$ Vehicle routing/assignment

$4.2 \mathrm{c}$ Other issues

\subsection{Demand management (DM)}

4.3a Sales forecasting

4.3b Bullwhip effect 


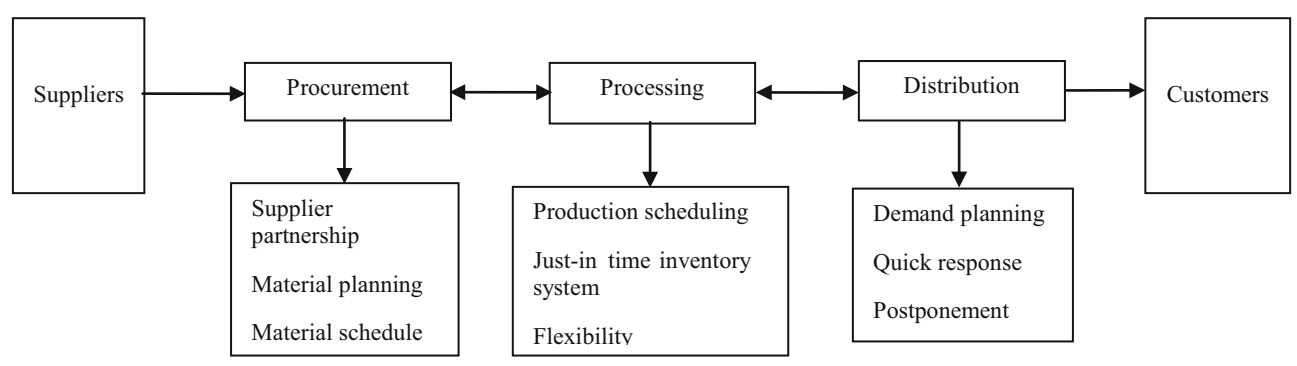

Figure 2. Supply chain management linkages.

4.4 Supplier relationship management (SRM)

4.5 Product development and commercialization (PDC)

4.6 Returns management (RM)

4.7 Customer service management (CSM)

4.8 Customer relationship management (CRM)

These processes are explained one by one in a sequential order in the following subsections.

\subsection{Manufacturing flow management (MFM)}

Manufacturing flow management (MFM) is the SCM process comprising all actions required to transport merchandises over the company in addition to attaining, employing, and bringing about manufacturing flexibility in the supply chain [23]. A framework on manufacturing flow in SCM is shown in figure 3. Figure 4(a), (b), and (c) shows the number of research articles breakup yearwise of MFM process, which includes Inventory management/Material planning, Supply chain planning, and Production planning, respectively.

As shown in figure 5, the first research article in relation to application of GA in MFM was presented in 1991 [5]. Till 2003, there are only a few studies, with less than two publications per year. This scenario however changed after 2004, where we can see a firm increase in the quantity of research articles, touching a highest in 2014. This indicates that additional work can be expected in the coming years. The researcher's curiosity can be acknowledged by means of the distribution of these research articles dealing with sub-processes. As shown in figure 6, Production planning has gained scholars' foremost interest. Predominantly, there are 55 numbers of studies pointing on Production planning that constitute $59 \%$ of total number of research papers in the MFM.

4.1a Inventory management/material planning: In SCM, Inventory management is a combined method for the planned controlling of inventories, over the whole interconnection of cooperating enterprise, starting with the supply source to the end worker [24]. The order distribution studies were solved by $[25,26]$ with the help of a heuristic methodology and a multicriteria GA in a demand-driven

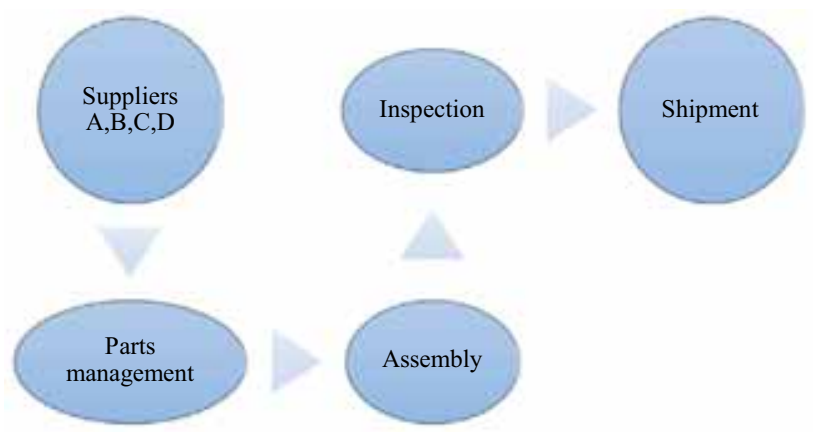

Figure 3. Manufacturing flow in SCM.

collaborative supply chain; afterward, the economic lot-size scheduling issues were dealt by GA heuristic approach $[6,7]$. In [6], GA is used for determining a fuzzy economic lot-size scheduling issue and in [7] GA is used to solve a joint economic lot-size model for integrated inventory control of a four-stage supply network in view of backlogged shortage. Vendor-managed inventory (VMI) issues are also discussed in various papers. In [8], GA and machine learning technique is used for modeling in addition to optimizing a vendor-managed replenishment system, while in [27] a two-echelon supply chain is studied for optimum operational parameters of VMI system using GAs; furthermore, in [28], a GA-neural network technique is suggested to lessen spare parts logistics overhead to deal the bill of material (BOM) configuration design issue.

Reference [29] presents a parameter-tuned GA to deal with multiproduct economic production quantity model, including space constraint, discrete delivery orders as well as shortages. Afterward, [30] used GA to optimize the emission inventory for a chemical transport model. In [31], GA is used with fuzzy arithmetic operations for simulation of VMI problems; in [32], a GA for VMI control system of two-level supply chain composed of a single vendor and a single retailer economic order quantity model is proposed; and in [33], a parameter-tuned GA is presented to optimize two-echelon continuous review inventory practices efficiently. In [34], authors proposed hybrid metaheuristics algorithms (HMHAs), which included GA, harmony search 


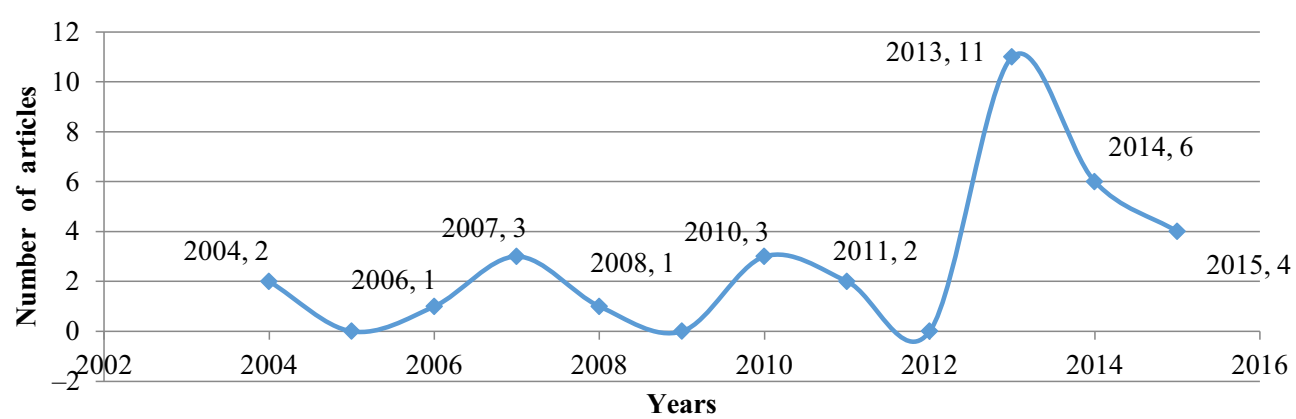

(a)

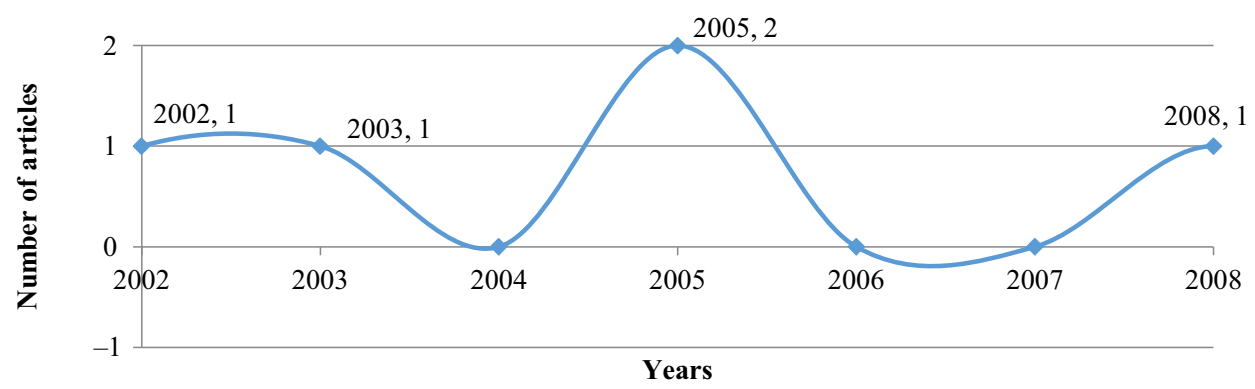

(b)

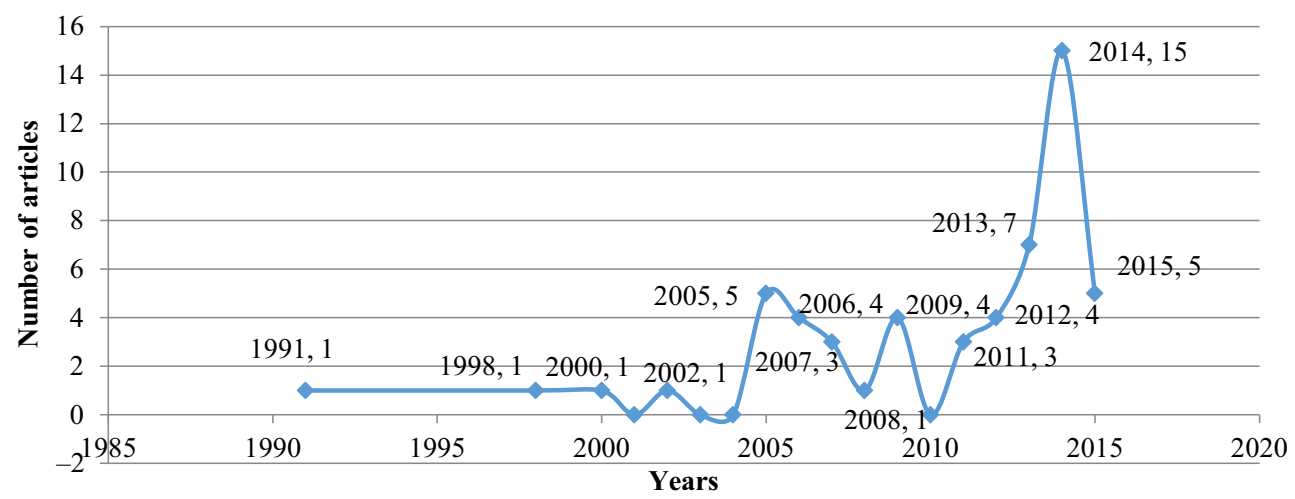

(c)

Figure 4. (a) Number of articles in inventory management/material planning sub-process of MFM, (b) number of articles in Supply chain planning sub-process of MFM, and (c) number of articles in production planning sub-process of MFM.

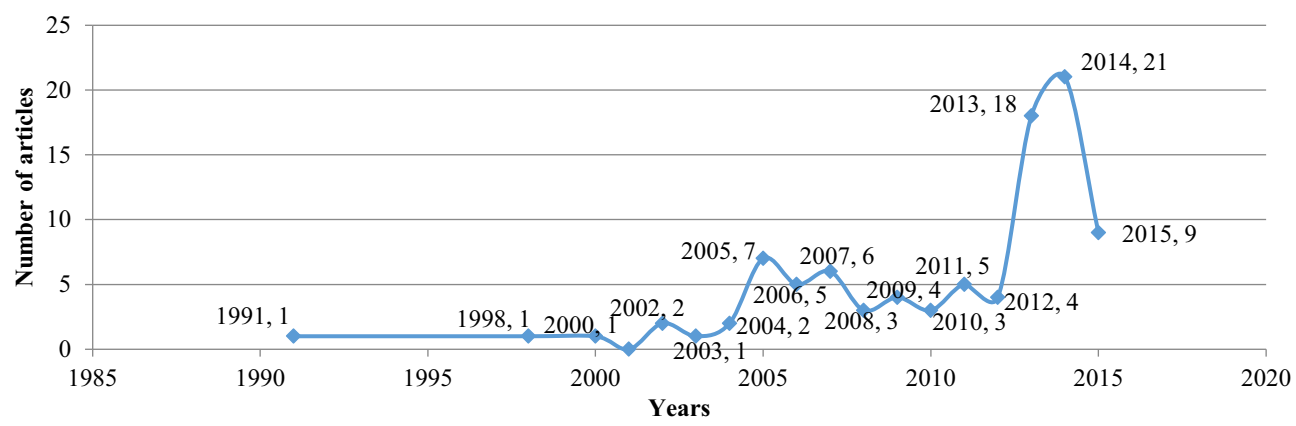

Figure 5. Total numbers of articles in sub-process of MFM.

(HS), particle swarm optimization (PSO), simulated annealing (SA), variable neighborhood search (VNS), and bees colony optimization (BCO) methods to solve the three-inventory problem, joint replenishment economic order quantity (EOQ) problem, newsboy problem, and stochastic review problem, in certain and uncertain 


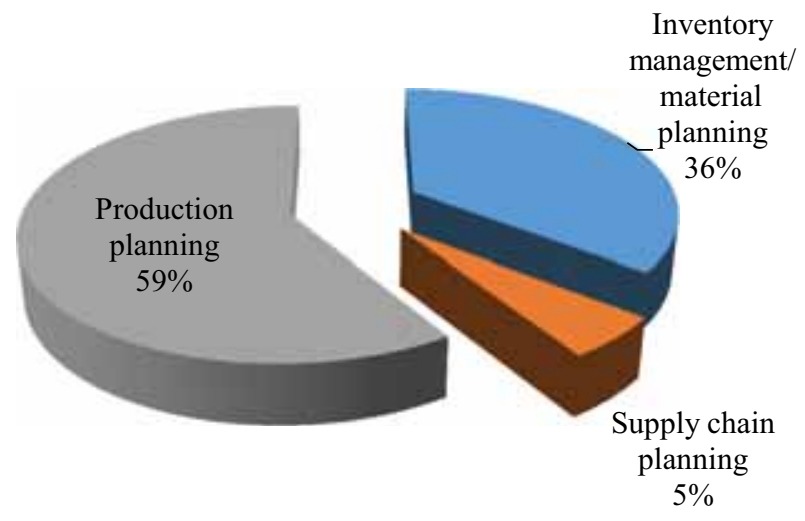

Figure 6. Distribution of articles in sub-processes of MFM.

environments such as stochastic, rough, and fuzzy environments with six different applications. In [35], authors offered a hybrid method of GA and fuzzy simulation (FS) to deal with inventory management issues alongside stochastic replenishments plus fuzzy demand. In [36], authors designed GA with varying population size method for a deteriorating item with time-varying demand and shortages of two-warehouse production inventory model; in [37], GA is proposed for supply chain inventory optimization with the best possible surplus stock level. In [38], the authors used GA to analyze a bi-objective inventory routing problem where the transportation cost along with the delivery cost is measured independently.

In [39], authors proposed a modified multicriteria optimization GA (MCOGA) established on the procedure for order distribution in collaborative supply chain. In [40] GA is used to optimized the two-stage collection distribution (TSCD) model with capacity constraints at both stages and results are compared with the standard operations research software LINDO for small problems. In [41], GA method including fuzzy simulation via contractive mapping is proposed to a vague production inventory model under volume flexibility; in [42], GA is used for optimization of VMI of multiproduct economic production quantity (EPQ) model with multiple constraints; in [43], an adaptive GA is proposed that produces good-quality solutions to the timedependent inventory routing problem (TDIRP). In [44], emphasis is laid on developing a fuzzy-rough (Fu-Ro) multi-objective decision-making imperfect production inventory model with GA.

Reference [45] presents a research on multiproduct, multiperiod continuous review inventory models based on a GA approach; [46] proposed a GA for an EOQ model of an item with imprecise seasonal time; [47] used GA for optimizing VMI of multiproduct EPQ model with multiple constraints. Authors in [48] used soft computing techniques in fuzzy-rough environment for a multi-objective multiitem inventory control problem. In [49], GA is used to solve a VMI system in a two-echelon supply chain used hybrid algorithm. Later in [50], a nondominated sorting genetic
algorithm-II (NSGA-II) with tuned parameters is used for optimizing a hybrid VMI and redundancy allocation problem in SCM.

In [51], problem of green VMI of multi-item multiconstraint EOQ model under shortage solved by a hybrid genetic and imperialist competitive algorithm is considered; [52] deals with the problem on inventory-based multiitem lot sizing by using a biased random key GA approach. In [53], a bi-objective VMI model with trapezoidal fuzzy demand is solved by two parameter-tuned multi-objective evolutionary algorithms, NSGA-II and nondominated ranking genetic algorithm (NRGA). In [54], an evolutionary algorithm (NSGA-II) for a new multi-objective location-inventory model is proposed.

4.1b Supply chain planning: Supply chain planning, in most enterprises, is the management of supply-facing and demand-facing activities to lessen disparities in a complete supply chain [55]. A supply chain planning framework is shown in figure 7. Reference [56] used GA to develop optimum resolutions through a two-stage optimization method for collaborative supply chain planning; afterwards, [57] showed that GA approach can be applied in multiplants supply chain, an optimum or near-optimum result with very high probability for integrated process planning and scheduling by means of decreasing total tardiness; in [58], the authors recommended that the evolutionary search method can be a noble substitute for the same problem discussed in [57]; furthermore, [59] presented a knowledgebased model for resource planning with several strategic as well as operational requirements of regional M-SMEs, later [60] considered a GA-based supply chain model to incorporate production as well as supply sourcing decisions.

4.1c Production planning: Production planning is an essential apprehension that together directly and indirectly makes a difference to the performance of the facility [61]. A classification framework on production planning in SCM is shown in figure 8. The first article in relation to application of GA in SCM was presented in 1991 [5], where a GA that can deal with the optimization of the job-shop problems is proposed; later, in [62], multi-objective GA (MOGA) is used for more convincing job-shop scheduling problems. The study in [63] shows that constrained GAs can also be used in scheduling problem. This GA uses a novel chromosome representation that takes into account machine as well as worker's assignments to jobs; subsequently, in [64], the general capacitated lot-sizing problem was resolved by at first using GA. The study in [65] suggested an adequate heuristic for optimizing sequence of customer orders.

Reference [66] presents an approach to solve a production and distribution problem based on a hybrid GA; the study in [67] shows a methodology to resolve distributed scheduling problems based on an adaptive GA with dominated genes. In [68], an approach is proposed to solve a due date-assigned distribution network problems based on multicriteria 


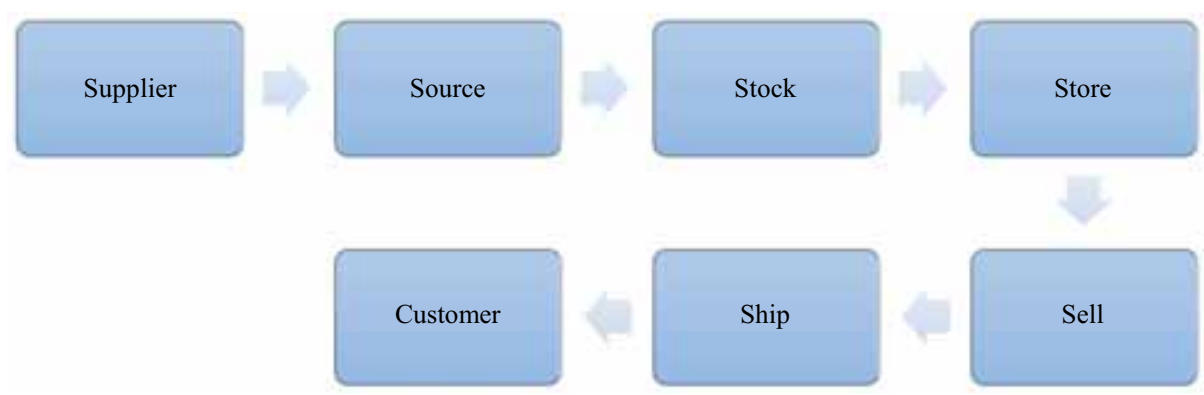

Figure 7. Supply chain planning framework.

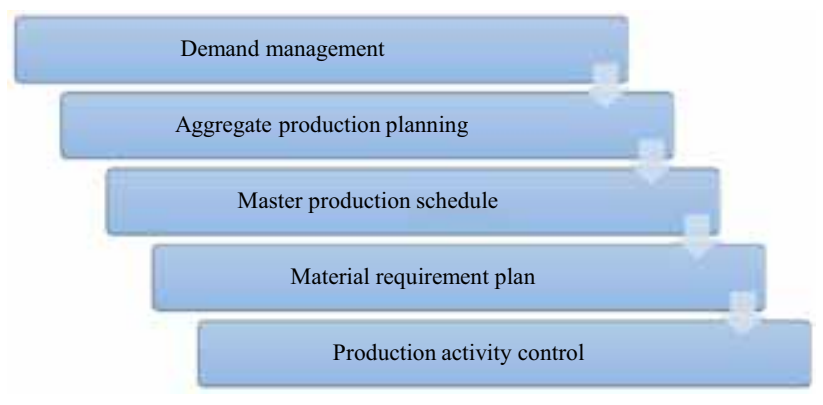

Figure 8. Productions planning in SCM.

genetic optimization. In [69], machine assignment problem is solved by a GA-based method. In [70], work is dedicated to simulation-based sequencing along with lot-size optimization, which shows that the GA is a dominant technique to determine good results for a production and inventory system. In [71], a GA-based approach is proposed, which solved iteratively a resource-constrained operations machines assignment problem and flexible job-shop scheduling problem; [72] presents optimization of a distributed scheduling problem in flexible manufacturing systems (FMS) based on GAs with dominant genes and [73] presents a GA-based approach for solving distributed FMS scheduling problems subject to maintenance; [74] proposed a GA with an mixed-integer linear programming (MILP) solver to studied the influence of flexible lead times on a paper producer, [75] applied GA for effective search of solutions for economic lot-scheduling problems; in [76], the authors analyzed batch manufacturing problems, where GA has been suggested to deal with job-shop problems; in [77], an efficient algorithm for a job-shop environment using GA is proposed to optimize lot streaming for product assembly; [78] proposed a study for distributed production scheduling environment using a modified GA-based approach; [79] solved lot streaming in a job-shop scheduling problem through GA and in [80] a hybrid chaos-based fast genetic tabu SA (CFGTSA) algorithm-based approach is proposed for performance optimization of a legality-inspired supply chain model, and in [81] GA approach is proposed to solve assembly job shop with part sharing.
The hybrid flow-shop scheduling solved by an adequate GA on the value of an optimum schedule, including multiprocessor task problems is shown in [82], while in [83] a modified GA (MGA) is presented where the objective is to minimize the total make span; [84] presented a GA-EDD algorithm using the earliest due date (EDD) dispatching rule for scheduling dual flow shops; while in [85], a modified GA is proposed for making manufacturing process plans in multiple parts manufacturing lines; [86] presented GA as well as Tabu search for solving the aggregate production planning (APP) model aimed at a two-phase production systems problem; [87] deals with the combinatorial explosion of alternatives associated with the consideration of different production scenarios as a computing efficient alternative using GA.

In [88], research on production scheduling with mold maintenance consideration based on a GA approach is presented. In [89], multi-objective GA is used for multicriteria study of the production scheduling of a Brazilian garment company. Afterward, in [90], planning algorithms for automatic job allocations is proposed based on group technology and GA.

Reference [91] addresses in the first part of the article modeling of the problems and discusses how the chromosome illustration of the real-coded GA (RCGA) can manage much flexibility of operations in the FMS and the second part of the article discusses the effectiveness of this hybrid approach to solve several test-bed problems. In [92], a method for optimizing the process planning with GA in enterprise resource planning (ERP) analyzed the factors relating to production planning decisions in ERP, where GA played undoubtedly a role of enhancing system performance.

Reference [93] demonstrates an interactive fuzzy-based genetic algorithm (FBGA) approach for solving a two products and two periods APP with some vulnerable managerial constraints such as imprecise demands, variable manufacturing costs, and in [94] a hybrid variant consisting of linear search, GA, and SA is proposed to capture the optimal solutions with respect to the vagueness factor and level of satisfaction for industrial production planning problems. Reference [95] presents an interactive MOGA 
method for solving the multiproduct, multi-period APP with forecasted demand, related operating costs, and capacity; in [96], a GA is developed to deal with the capacitated lot sizing in addition to scheduling problem with sequence-dependent setups, setup carryover, together with backlogging.

Reference [97] presents greedy rolling horizon search (GHRS) technique for solving production planning problem in supply chain networks. Although this paper does not use GA as the main algorithm, comparative analysis of GHRS is done with GA. Results show that GHRS performs better than GA. In [98], an alternant iterative GA is proposed to integrate production planning and scheduling for a mixed batch job-shop environment; in [99], a two-level soft drink production problem is solved using GA and mathematical programming approach, while in [100], a controlled elitist nondominated sorting GA (NSGA) and NSGA-II is used for multiobjective process planning and scheduling (PPS); in [101], PPS problem is solved using hybrid multiobjective algorithm combining the properties of vector-evaluated genetic algorithm (VEGA) and pareto-dominating and -dominated relationship-based fitness function (PDDRFF). Reference [102] presents a literature survey, classification, and analysis to solve scheduling problems on FMS by using GAs; in [103], job process planning and scheduling (PPS) in batch production is solved using a GA-based approach.

Reference [104] presents an improved GA approach for joint optimization of production planning and supplier selection incorporating customer flexibility; reference [105] demonstrates the application of hybrid GA on test bed scheduling problems, and reference [106] presents a process plan modeling framework for multiple parts process planning in serial-parallel flexible flow lines using GA. Reference [107] presents a solution method based on GA with fixed and variable length chromosomes for multiple parts process planning in serial-parallel flexible flow lines. In reference [108], a multiobjective job-shop scheduling problem is solved using a dispatching rule-based GA with fuzzy satisfaction levels.

In reference [109], reentrant flow-shop scheduling problem with time windows is solved using hybrid GAbased on auto-tuning strategy. Reference [110] presents a GA approach for coordinated scheduling of the transfer lots in an assembly-type supply chain, while in reference [111] an integrated discrete PSO and extended priority-based hybrid GA is proposed for multistage production distribution under uncertain demands. In reference [112], unequal individual GA with intelligent diversification is used for lot-scheduling problem in integrated mills using multiple-paper machines; in [113], integrated PPS is optimized by an object-coding GA. In [114], a flow-shop sequence-dependent group scheduling problem is solved by minimizing make span using a hybrid GA combining features of random sampling search with GA.

\subsection{Order fulfillment}

An order that completely fulfills customer requirements within its completion is termed as a "perfect order" [115]. Order fulfillment (OF) is one of the vital parameters to reflect client service performance. A pictorial cycle on $\mathrm{OF}$ in SCM is shown in figure 9. Figure 10(a), (b), and (c) shows the number of research articles breakup yearwise for a process that includes logistics and networks planning, vehicle routing, and other issues, respectively.

As shown in figure 11, the quantity of research papers relating to $\mathrm{OF}$ increase gradually, through some rise and fall, between 1998 and 2009. By contrast, a histrionic growth can be observed from 2010 to 2014. As shown in figure 12, out of the 90 papers on OF in SCM, 52\% of the studies concentrated on logistics network design/planning problem; however, the other studies focused on vehicle routing and other issues.

4.2a Logistics network design/planning: To improve a longstanding optimal supply chain, one of the best comprehensive tactical decisions has been recognized as the network design problems [116]. Reference [117] proposed GA to solve network design problem that can be relatively common in nature; references [118-124] proposed to solve dynamic logistics network design as well as planning problem, such as multistage logistic network design and optimization.

Reference [118] discussed a spanning tree-based GA (stGA) approach to find the best production/distribution design in multistage logistic network. Reference [119] used

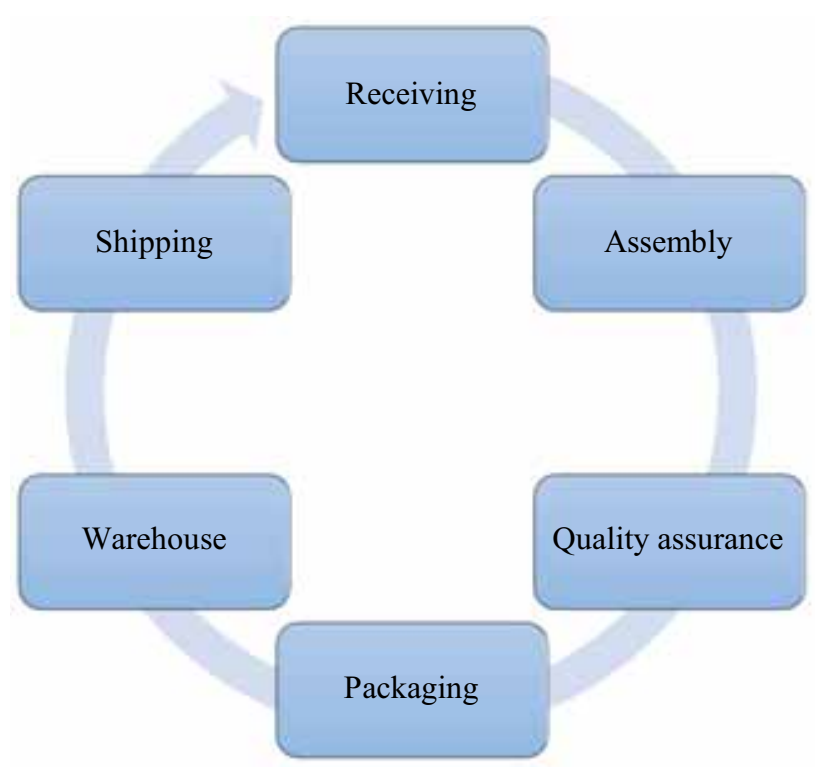

Figure 9. Order fulfillment cycle. 


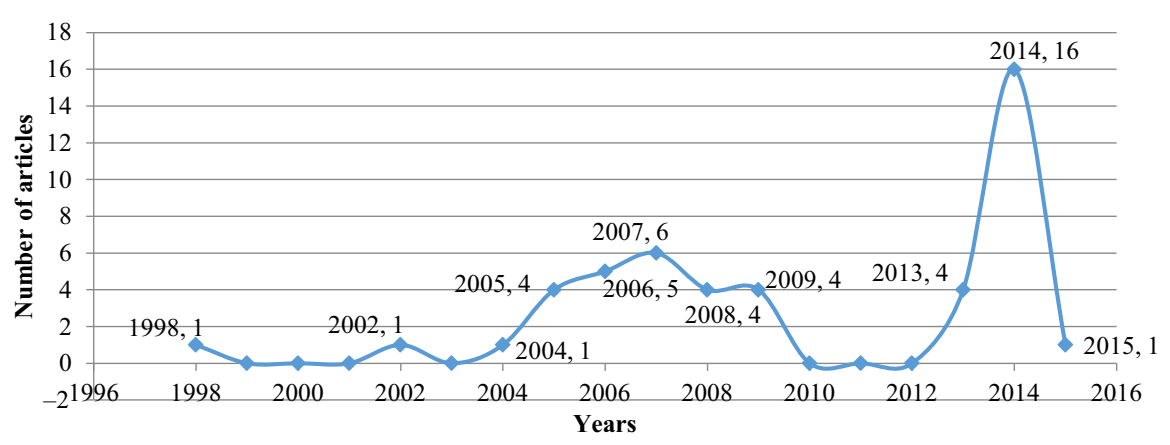

(a)

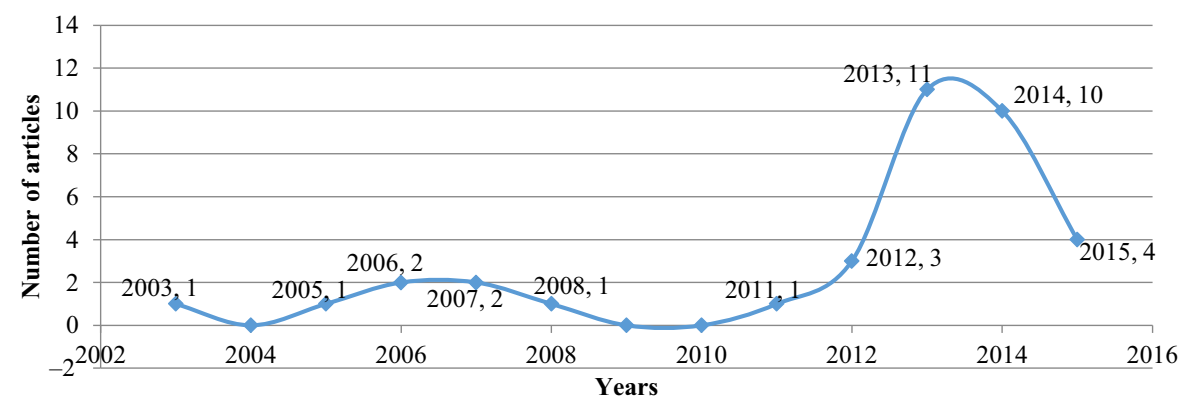

(b)

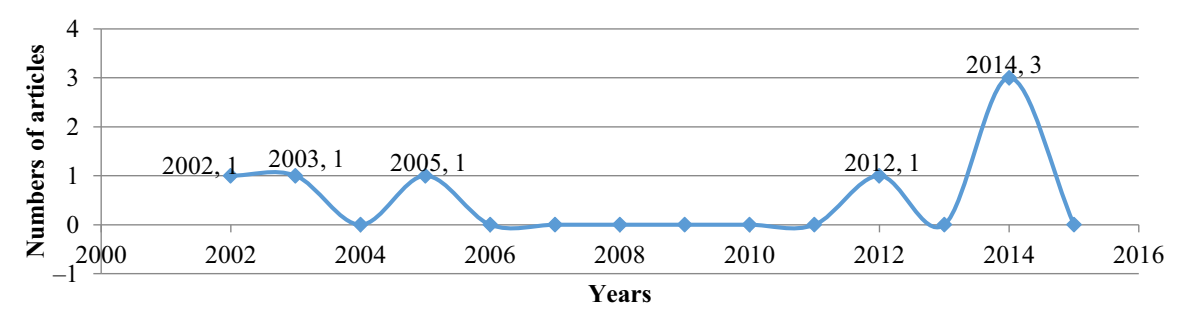

(c)

Figure 10. (a) Number of articles in logistics and network design sub-process of OF, (b) number of articles in vehicle routing subprocess of $\mathrm{OF}$, and (c) number of articles in other issues sub-process of $\mathrm{OF}$.

an enhanced GA based on the Prüfer number in addition to the adequate capacity coding to optimized unbalanced multistage logistics systems. In [120], st-GA is used in random fuzzy environment for multiobjective supply chain networks optimum model and its applications to the Chinese liquor industry; in [121], researchers determine the optimum solution of the continuous network design problem (CNDP) using two global approaches composed of GA as well as SA; and in [122] researchers applied a hybrid nondominated sorting GA (NSGA) to optimize the total cost along with service level aimed at just-in-time (JIT) distribution in a supply chain. In [123], researchers solved single-source, multiproduct, multistage supply chain network (SCN) design with steady-state GA (ssGA); later, in [124], researchers proposed a GA-based heuristic method for a two-stage supply chain distribution problem related with a fixed charge.

Authors in [125] solved distribution network problems by multi-criteria genetic optimization; in [126], authors used GA in distribution network problems for optimization of OF. References [127, 128] show freight transportation planning; [127] use GA and probability theory, which affects the determination of the tactical model, and in [128], authors solved nonlinear fixed charge transportation issue using the spanning tree-based GA method; afterwards, in [129], authors solved multitime period production/distribution planning problem with the application of a novel method named hybrid spanning tree-based GA (hst-GA); and in [130], the authors suggested a fuzzy-GA that solved integrated production/distribution planning model in the SCM; references [131, 132] deal with logistic process optimization. In [131] weighted fuzzy optimization is used for logistic systems and in [132] the online reoptimization of a logistic scheduling problem is solved with the help of GA along with ant colony optimization (ACO). In [133], the authors suggested vehicle transshipment planning in seaport terminal. References [134, 135] present a study on network design problems; whereas in [134], the authors suggest a knowledge-based method that assists in procurement decision making, and in [135], the authors 


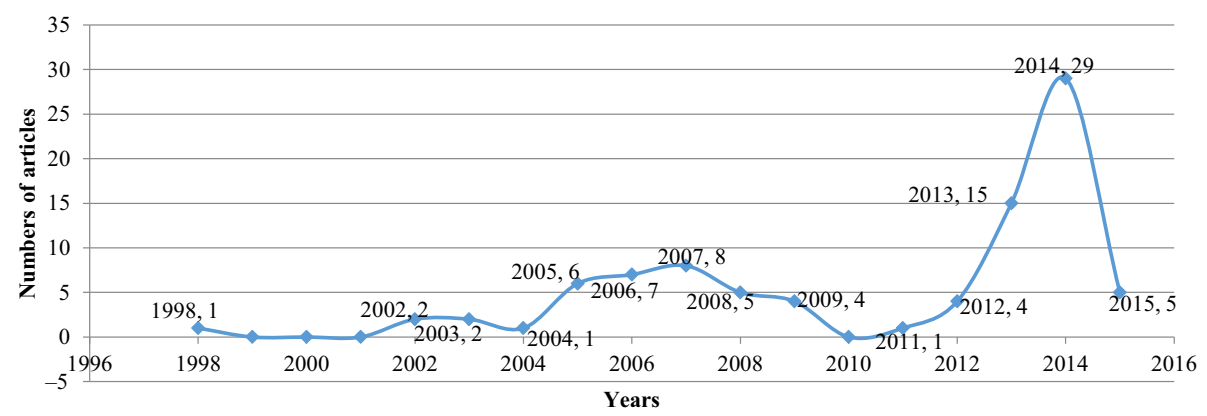

Figure 11. Total numbers of articles in sub-process of OF.
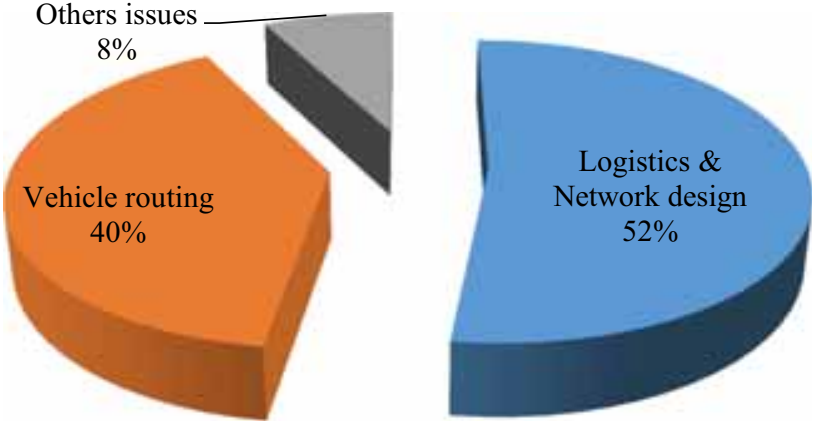

Figure 12. Distribution of articles in sub-processes of OF.

determined the set of pareto-optimal solutions for multiobjective supply chain network (MO-SCN) design problem using a GA-based approach.

Reference [136] presents a GA method for freight transportation planning to reduce overall shipment costs. Subsequently, authors in [137] employed GA for solving the problem of container shipping and repositioning. In [138], the authors unite GA and a set of constructive heuristics for the distribution of ready-mixed concrete. References [139, 140] provide a study on third-party logistics (3PLs) services integration; researchers in [139] proposed a hybrid GA-based heuristic optimization/simulation modeling method for the design of a delivery setup of 3PLs; researchers in [140] suggested a GA-based heuristic that involves genetic operations along with simplex transshipment algorithm 3PLs.

In [141], the authors applied GA to attain improved cooperation, together with superior collaborative work in a collaborative SCN. Authors in [142] suggested interval hierarchical OD demand based on an interval GA, which is for discrete logistics network design model; in [143], authors provided a continuous equilibrium network design model of stochastic demand and supply solved by Monte Carlo simulation-based GA. In [144], the authors employed a multiobjective GA (MOGA) for the resolution of the consequential NP-hard combinatorial optimization problems. In [145], the authors customized Pareto-based multi-objective evolutionary algorithm and NSGA-II to determine the compromise solutions for a readily adapted three-level logistic network design. Later in [146], the authors used priority-based GA for combined closed-loop logistics network design along a fuzzy-random programming.

In reference [147] transportation problem is solved using fuzzy guided multi-objective evolutionary algorithm model, and in [148] two-way approximation GA is presented for supply chain distribution network of bi-level programming model. In [149], the authors have used a hybrid PSO and GA for closed-loop SCN design in largescale networks; in [150], optimization of closed-loop SCN is presented with crisp and fuzzy objectives by a GA approach; in [151], a fuzzy reverse SCN design is presented using hybrid algorithms; and in [152], authors optimize the green agricultural products SCN using a transforming quantum-inspired GA. Reference [153] presents optimization of defective goods supply chain costs using GA.

In reference [154], authors used GA for design of SCNs with supply disruptions; in [155], the authors used GA for optimization of a multistage SCN. In reference [156], response surface method (RSM) and GA are used for optimization of logistics cost and inventory design of an organizations logistics network. In [157], GA is used for presenting an optimization model for reverse logistics network under stochastic environment. Authors in [158] solved emergency logistics scheduling using greedysearch-based MOGA; reference [159] presents a case study of automotive wiring harnesses based on optimization of reverse logistics network by GA. In [160], authors have applied GA on reverse logistics for optimization of network site for e-commerce; authors in [161] proposed GA for optimization of logistics network of import crude oil in China, and in [162], GA is used for design of multiproduct/multiperiod closed-loop reverse logistics network. In [163], NSGA-II and NRGA are proposed for bi-objective optimization of a problem of multiproduct, multiperiod, three-echelon supply chain under uncertain environments.

$4.2 \mathrm{~b}$ Vehicle routing/assignment: The vehicle routing problem (VRP) is made up of a number of customers, each needing a fixed mass of goods to be transported. Vehicles dispatched from a single work shop must transport the 


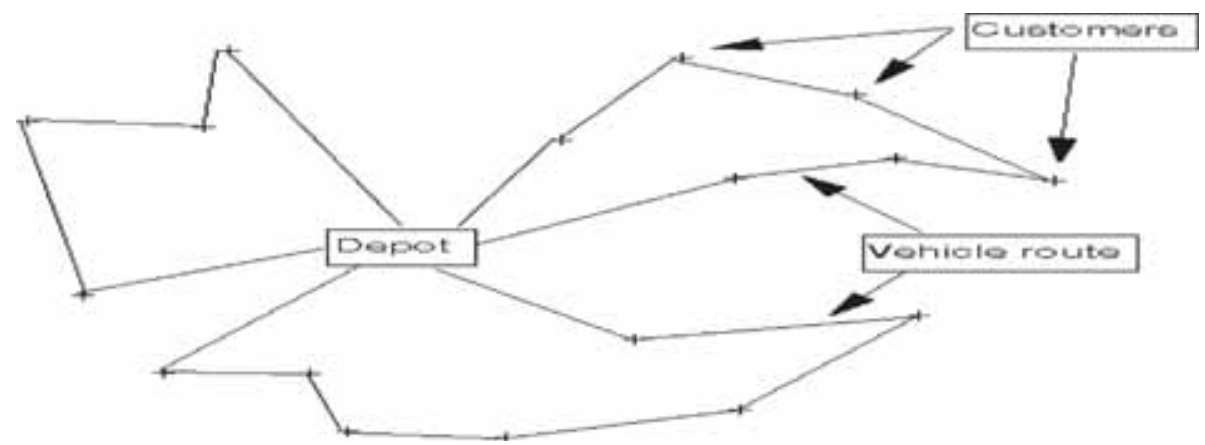

Figure 13. Route of vehicle in a depot (source: http://people.brunel.ac.uk/ mastjjb/jeb/or/vrp.html).

merchandises required, and then come back to the work shop. The problem is to fix distribution routes and give nominal cost [164]. Vital VRP have picked logistics administrators and researchers' consideration after 2000. A pictorial route of vehicle in a depot is shown in figure 13. Many GA-based papers are available in literature for dealing with VRP. In [164], the authors used GA for the first time in 2003 for VRP; in [165], the authors proved that a GA-based methodology is competent to determine superior solution to fulfill the growing pressures on readily adapted and speedy transportation services. References [166-168] show that, in a simple supply chain, a hybrid GA (HGA) is extra encouraging in reducing transportation charge; in [166], the authors proposed an HGA for the finite horizon economic lot along with delivery scheduling; in [167], authors offered a critical literature review on different heuristic shortest-path algorithms, and in [168], for logistics distribution centers, location problem authors used integrated GA, FS algorithm, and Tabu search algorithm to seek better approximate solution.

References [169, 170] presented promising results on VRP along with pickup and delivery sequence constraints; in [169], the authors proposed a cluster along with search heuristic to deal with the VRP with delivery as well as pickup, and in [170], the authors developed a simple GA to solve multidepot VRP (MDVRP) by integrating three hard optimization problems; in [171], authors offered a novel kind of geometric shape-based genetic clustering algorithm for multi-depot VRP, and in [172], an improved savings heuristics along with GA for bi-objective VRP with forced bi-backhauls (BVFB) is proposed. References [173, 174] present a hybrid approach that merge a GA with an iterated local search (ILS) to deal with the location-routing problem (LRP) efficiently. In [175], authors proposed an effective hybrid GA, including progressive diversity control method for a large class of time-constrained VRP.

Reference [176] presents a new niche cellular GA algorithm to solve the VRP with time window, and in [177], a hybrid GA is applied to the capacitated VRP (CVRP); in [178], the authors suggested improved GA to solve the VRP along time window by applying an optimized crossover operator; in [179], the authors recommended a hybrid genetic and immune algorithm to deal with the VRP along with limited capacity. Authors in [180] introduced an adaptive evolutionary approach that apply a GA in an adaptive tactic for real-time VRP with dispatching; in [181], the predictability of GA performance is examined on the VRP using information-theoretic fitness landscape measures; in [182], authors propose a new way to calculate the adaptive probability in the cross operator with an improved GA.

In [183], authors proposed a hybrid GA for the multidepot open VRP, and in [184] the authors worked on enhancing localized GA for large-scale capacitated VRP solution by introducing selective search version of the automated problem decomposition strategy, a faster genotype-to-phenotype translation scheme, and various search reduction techniques; reference [185] presented a work on traffic volume and vehicle utilization, which are closely related to the cost of vehicle traffic, a vehicle scheduling model with the minimum fuel cost, and fixed cost is established. According to the requirement of real-time and complicacy of the vehicle scheduling, a cloud-adaptive GA is proposed by combining cloud model theory with GA.

In [186], a GA is proposed to deal with the bi-objective VRP with time windows simultaneously, considering total distance and distance balance of active vehicle fleet. A new complex chromosome is used to present the active vehicle route. In [187] GA is used for solving the dynamic VRP, while in [188] authors solved the periodic VRP with time windows by a hybrid generational GA and in [189] VRP is solved with the help of a new MOGA: called fitness-aggregated GA (FAGA).

In [190], the authors solved a multi-depot open VRP using a hybrid GA; in [191], authors solved multi-objective VRP with time windows, with the help of partially optimized cyclic shift crossover for MOGA. Reference [192] presents optimization of warehouse order-picking routes using vehicle routing model and GA. Reference [193] proposed FAGA for the solution of multi-objective VRP with time windows; in [194], authors used fuzzy cost coefficients and hybrid GA to solve VRP; in [195], authors present a parallel multi-start NSGA-II algorithm for multi- 


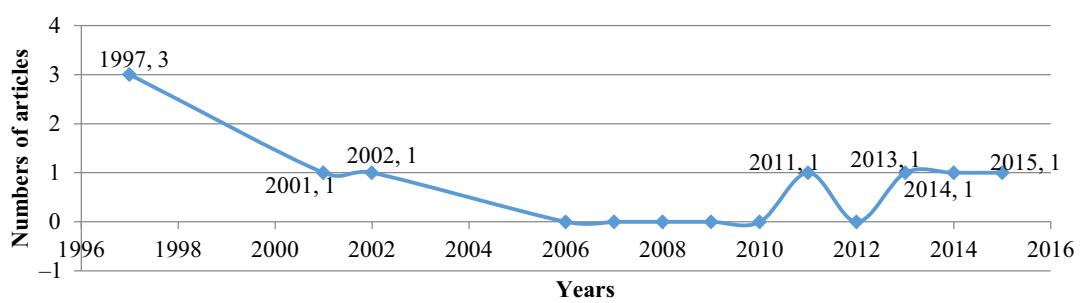

(a)

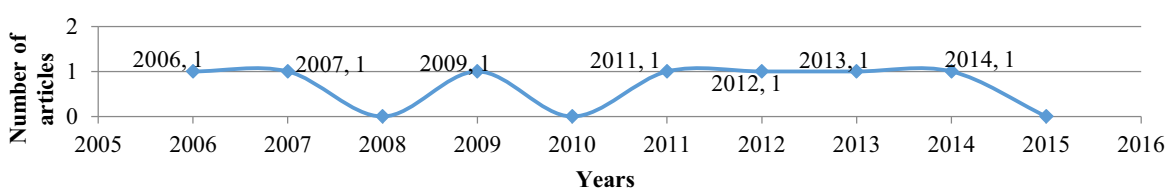

(b)

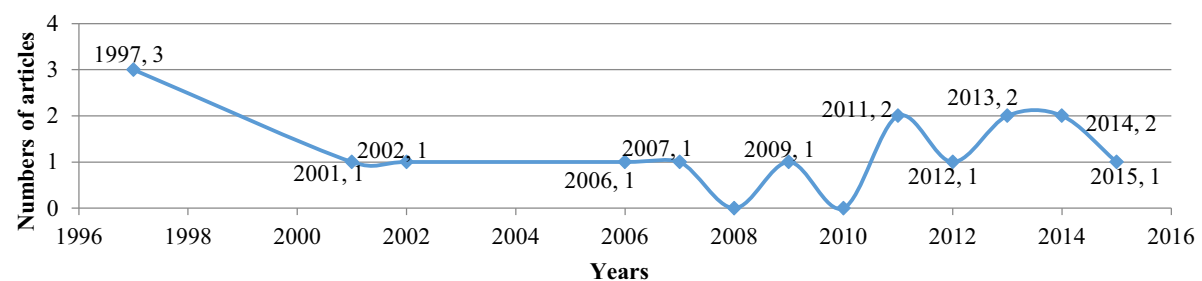

(c)

Figure 14. (a) Number of articles in sales forecasting sub-process of DM, (b) number of articles in bullwhip effect sub-process of DM, and (c) total numbers of articles in sub-processes of DM.

objective energy reduction VRP; in [196], authors solved multi-depot heterogeneous VRP with simultaneous pickup and delivery time windows using an improved GA. Reference [197] presents a survey of GAs for solving multidepot VRP. In [198], authors present a GA approach for two-level vehicle routing with cross-docking in a threeechelon supply chain.

4.2c Other issues: Authors in [199] developed a new balanced star spanning forest formulation including GA to deal with the balance allocation problem, which is known to be NP-hard, and in [200], authors employ a GA aimed to determine pareto-optimal solution for dealing with problems in a small portion of interval; reference [201] regulates the optimum arrangement of shipping choices to reduce overall logistics costs using a genetic or evolutionary algorithm (GA-EA).

Reference [202] used GA for optimizing replenishment policies of single-warehouse multiretailer system; reference [203] proposed GA for solving and modeling supply chain facility location problem; in [204], authors solved the economic manpower shift planning problem with the help of GA, and in [205], the capacitated facility location problem is solved using hybrid fireflyGA.

\subsection{Demand management}

Demand management (DM) comprises all the demand activities, including market sensing, market creating, marketing, and demand capturing. It has two major subpractices: sales forecasting and bullwhip effect [206]. Figure 14(a) and (b) show graphically the number of articles corresponding to sub-practices of DM, namely, sales forecasting (9 articles) and bullwhip effect (7 articles). Figure 14(c) shows total number of research articles in subprocesses of DM and figure 15 shows the distribution of articles in sub-processes of DM.

4.3a Sales forecasting: Sales forecasting models perform a substantial part in marketing of goods and services planning [1] and it is one of the main tactical exercises in managerial decision-making practices for DM [207]. In [4], the authors used GA in SCM for computerized causal forecasting system, while in [208], authors presented a forecasting algorithm made up of two loops: the genetic forecasting loop and the pattern learning loop. Reference [209] presents a combination of two techniques, fuzzy theory and GA for the solution of forecasting problems. In [210], authors proposed genetic fuzzy predictor ensemble for forecasting a time series problem. In [206], authors solved sales forecasting system based on fuzzy neural network problem with generated initial weights by GA; in [1], authors extracted the rule base of the fuzzy expert system and K-means genetic fuzzy system (KGFS) in building a sales forecasting expert system using GA.

In [211], GA is used for optimizing neural network for coal sales prediction in some large coal enterprise; reference [212] established a novel forecasting model integrating decision tree (DT) algorithms and GA to construct a 


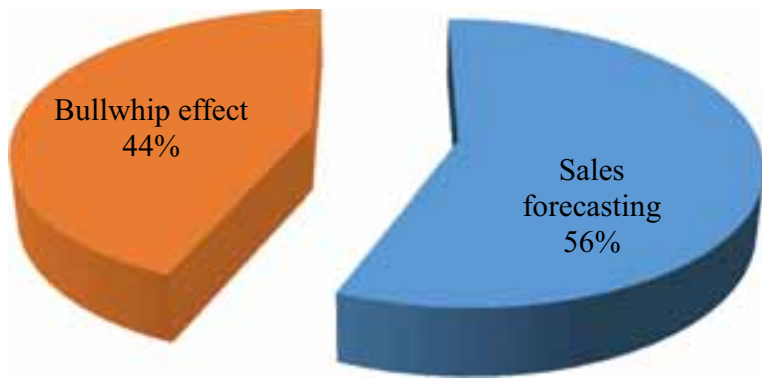

Figure 15. Distribution of articles in sub-processes of DM.

sales predictions system based on historical data and the most optimized decision tree. In [213], authors proposed a GA to optimize backpropagation (BP) neural network structure on car sales forecasts.

4.3b Bullwhip effect: A phenomenon through which a slight discrepancy in the demand from end customer effects massive deviations as it drives upstream is called bullwhip effect [214]. Reference [215] suggests that the GA can minimize the bullwhip effect with random customer demand, combined with deterministic and random lead times.

Authors in [216] showed that GAs can minimize the bullwhip effect with the optimal ordering policy of difficult supply chains. Reference [217] investigates whether GAs can adequately minimize the bullwhip effect in an efficientresponsive supply chain.

In [218], GA and control engineering (PI and PID controllers) are used as tools for the bullwhip minimization in supply chains; in [219], GA is used to minimize the bullwhip effect and to find optimal ordering quantity in a multistage supply chain. In [220], a parallel GA is proposed to reduce the bullwhip effect and cost in an automotive supply chain. In [221], evolutionary multi-objective metaheuristics is used for optimizing of bullwhip effect and net stock amplification.

\subsection{Supplier relationship management}

SRM is an exercise involved in dealing with finest vendors and finding new ones, at the same time as minimizing costs, accomplishing procurement predictable along with repeatable, bring together buyer understanding, and take out the profits of supplier partnerships [222]. Some pioneering work in SRM can be found in [223-226]. A pictorial classification of the different steps of supplier relationship management in SCM is shown in figure 16, and figure 17 shows the number of articles in SRM.

Reference [227] used for optimization of incentive system to achieve competence of supply chain allies to make sure the long-standing tactical relations with a GA technique, whereas in [228] GA is applied with budget constraints for a stochastic demand multiproduct vendor selection model; in [229] two MOGA are applied to find a set of pareto-optimal solutions that can develop additional solutions for the green partner selection using weighted sum tactic. In [230], authors solved a stochastic demand multiproduct supplier selection model along with budget constraints applying GA. In [231], authors applied GAbased gray goal programming model for evaluation and selection of the suppliers, and in [232], authors selected GA parameters for solution. The authors also analyzed the sensitivity of the multiple supplier-multiple buyer collaborative supply chain model parameters to understand how variations in the model parameters affect the related total costs. Reference [233] presents a case study using a GA for supplier selection decision enhancement.

\subsection{Product development and commercialization}

The product development and commercialization (PDC) practices need adequate planning along with execution all through the supply chain, and if managed in the approved manner can deliver a sustainable competitive benefit [234]. A pictorial classification framework on product development and commercialization in SCM is shown in figure 18 and figure 19 shows the number of articles in PDC.

In [235], a hybrid multi-objective (GA-MCDM) approach is presented for selecting the best portfolio alternative for new product development in the pharma industry. Reference [236] presents an adaptive GA for task allocation optimization in collaborative customized product development. In [237], authors proposed an approach for optimal affective product design using mined rules based

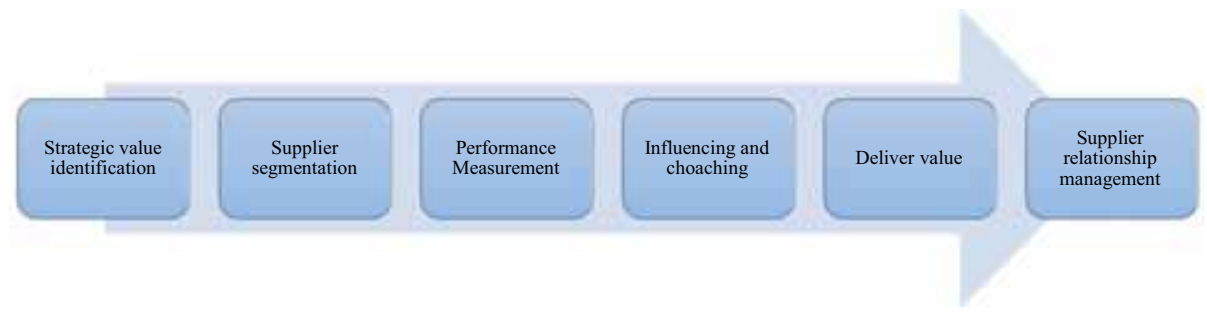

Figure 16. Different steps of SRM in SCM. 


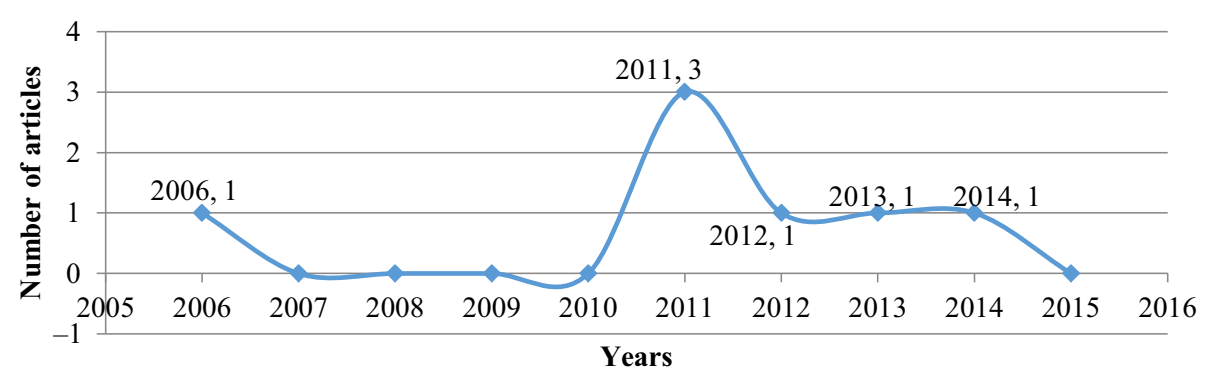

Figure 17. Number of articles in SRM process.

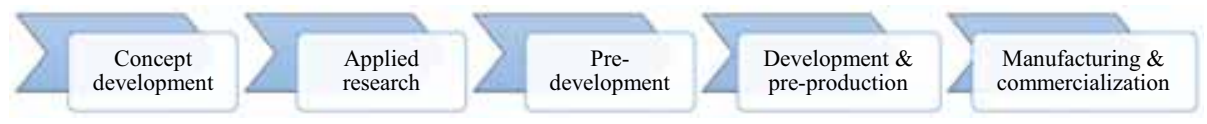

Figure 18. Product development and commercialization steps.

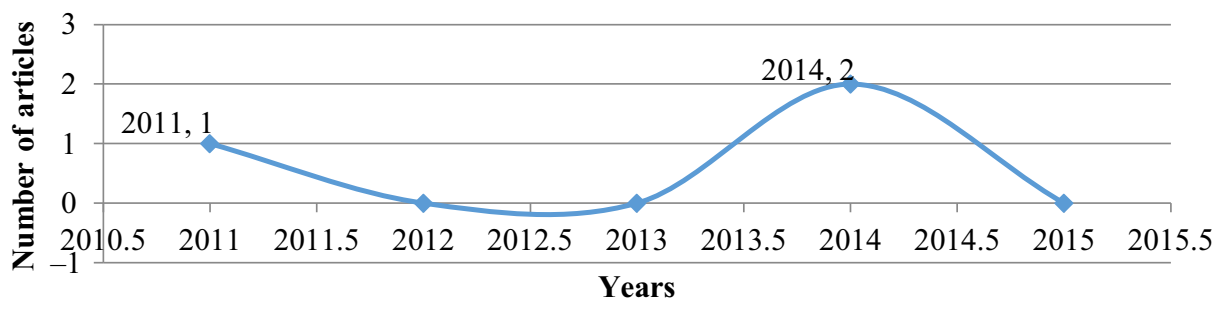

Figure 19. Number of articles in PDC process.

on guided-search GA. It seems that there are very few research papers addressing this process.

\subsection{Returns management}

Returns management (RM) is the SCM practice by which activities associated with returns; reverse logistics, gate keeping, and avoidance are managed within the enterprise through crucial associates of the supply chain [238]. The number of articles in PDC is shown in figure 20.

References [239, 240] give GA-based method to deal with reverse logistics problem of handling reverted goods, where [239] presented a mixed-integer, nonlinear programming model along with a GA that can deal with these problems containing equally spatial plus temporal consolidation of reverted produces; reference [240] presents a mixed-integer, nonlinear programming model including GA that can settle the reverse logistics problem; in [241], the authors established an optimum solution to deal with the reverse logistics network design problems, in order to search for the optimal solution of this a mixed-integer nonlinear programming model (MINLP); in [242], authors proposes a mixed-integer programming model and a GA to solve the similar issues from third-party logistics service providers' viewpoint.

In reference [243], authors proposed a hybrid qualitative and quantitative methodology by means of fuzzy cognitive maps along with GA to model as well as estimate the competence of radio frequency identification (RFID)-enabled reverse logistic activities; in [244], authors presented a GA that can deal with the stochastic network design problem in a closed-loop supply chain; subsequently, [245] used GA and artificial immune system to present an optimization model for product returns; in [246], a competent hybrid genetic-simulated annealing algorithm (HGSAA) is proposed to deal with the NP-hard problem, of a location-inventory-routing problem; in reference [247], authors researched on spare part returns in stochastic deteriorating manufacturing system under a condition-based maintenance policy using simulationbased GA approach; and in [248], the authors proposed an improved adaptive GA (IAGA) to solve optimization of location inventory routing problems (LIRPs) considering the cost of the returned products and the retailers' time-satisfaction degree into account; in [249], an optimization model for product returns is solved using GA and SA. 


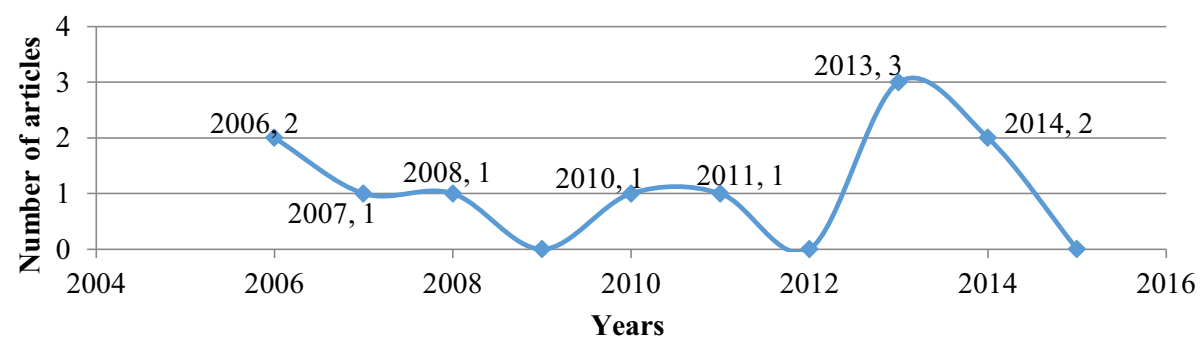

Figure 20. Number of articles in RM process.

Table 1. Annual distribution of number of papers in respective subject processes.

\begin{tabular}{|c|c|c|c|c|c|c|c|c|c|}
\hline Years & MFM & $\mathrm{OF}$ & DM & SRM & PDC & RM & CSM & CRM & Total \\
\hline 1991 & 1 & & & & & & & & 1 \\
\hline 1997 & & & 3 & & & & & & 3 \\
\hline 1998 & 1 & 1 & & & & & & & 2 \\
\hline 2000 & 1 & & & & & & & & 1 \\
\hline 2001 & & & 1 & & & & & & 1 \\
\hline 2002 & 2 & 2 & 1 & & & & & & 5 \\
\hline 2003 & 1 & 2 & & & & & & & 3 \\
\hline 2004 & 2 & 1 & & & & & & & 3 \\
\hline 2005 & 7 & 6 & & & & & & & 13 \\
\hline 2006 & 5 & 7 & 1 & 1 & & 2 & & & 16 \\
\hline 2007 & 6 & 8 & 1 & & & 1 & & & 16 \\
\hline 2008 & 3 & 5 & & & & 1 & & & 9 \\
\hline 2009 & 4 & 4 & 1 & & & & & & 9 \\
\hline 2010 & 3 & & & & & 1 & & & 4 \\
\hline 2011 & 5 & 1 & 2 & 3 & 1 & 1 & & & 13 \\
\hline 2012 & 4 & 4 & 1 & 1 & & & & & 10 \\
\hline 2013 & 18 & 15 & 2 & 1 & & 3 & & & 39 \\
\hline 2014 & 21 & 29 & 2 & 1 & 2 & 2 & & & 57 \\
\hline 2015 & 9 & 5 & 1 & & & & & & 15 \\
\hline Total & 93 & 90 & 16 & 7 & 3 & 11 & & & 220 \\
\hline
\end{tabular}

\subsection{Customer service management}

CSM deals with a service-focused process of managing tie up between clients and service provider [250]. We could not find any relevant paper in this area.

\subsection{Customer relationship management}

CRM is a widely practiced model for managing a firm's relations with customers, consumers, in addition to sales scenarios [251]. Here also the authors could not find any paper on CRM where GA is used.

\section{Discussions}

- Distribution of articles as per main processes and subprocesses of SCM
- As shown in table 1 , several research papers have contributed to seven broad categories of SCM processes. The MFM is the most popular process targeted by GA applications. The research papers about $\mathrm{OF}$ are slightly more common than the papers regarding DM. It is clear therefore that papers for those three major SCM processes are considerably more than those in other SCM processes.

- Pie diagram given in figure 21 shows the percentage of papers concentrating on the major processes of SCM. It shows that out of total research papers reviewed for this study, MFM contributes $42 \%$ of the total distribution and is the most popular process in SCM where GA is used. MFM is closely followed by OF, having $41 \%$ papers with GA application. Remaining $17 \%$ papers consist of papers focused on DM (7\%) and other issues such as SRM, PDC, RM contributes $10 \%$ to this distribution. 


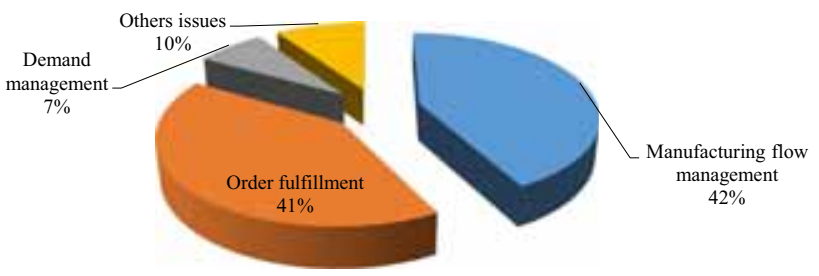

Figure 21. Proportion of articles in SCM major processes.

- Table 2 provides a break up in detail for the connection between researchers and respective SCM research area on yearly basis. The number of research articles and the researchers working for GAs applications in SCM-related areas has steadily increased since 2000 .

- As shown in table 3, out of the surveyed 220 papers, 93 are concerned with the MFM, in which sub-processes include inventory management/ material planning (33), supply chain planning (5) and production planning (55). While 90 out of remaining 127 papers concerned with the OF, based on available practices from the literature, include sub-processes logistics \& network design (47), vehicle routing (36) and others issues (7), for tackling the problem. Subsequently, 16 papers utilize DM practices, which include sales forecasting (9) and bullwhip effect (7). Finally, the remaining 21 papers are based on the processes concerned with SRM (7), PDC (3), and RM (11).

- The graph in figure 22 shows that there has been a considerable increase in the number of articles since 1991, where GA is applied for dealing with different aspects of SCM. In 2014, the number of articles with GA application in SCM touched 57.

- Publication of articles in leading journals

- As presented in table 4, 23 papers were published by Expert Systems with Applications, while 15 of total papers were published by Computers and Industrial Engineering, and 12 articles by International Journal of Production Economics. European Journal of Operational Research, Journal of Intelligent Manufacturing, Computers \& Operations Research. Journal of Advanced Manufacturing Technology and Journal of Intelligent Manufacturing as well the key journals acknowledged by scholars.

- From the publication point of view, we see that almost all the major journals have covered articles belonging to SCM. As shown in table 4, the top contributor is a journal focused on computer science (Expert Systems with Applications), on computer science and industrial engineering/operations research (Computers and Industrial Engineering, Computers \& Operations Research), and wellestablished journals in the Operations Management and Manufacturing areas (International Journal of Production Research, European Journal of Operational Research, International Journal of Production Economics, Journal of Intelligent Manufacturing, Journal of Advanced Manufacturing Technology); contributions can be also retrieved in more traditional journals from several disciplinary areas, such as Informatics and Computer Science Intelligent Systems Applications

Table 2. Annual summaries of articles in respective subject processes.

\begin{tabular}{|c|c|c|c|c|c|c|c|c|}
\hline Years & MFM & $\mathrm{OF}$ & DM & SRM & PDC & RM & CSM & CRM \\
\hline 1991 & [5] & & & & & & & \\
\hline 1997 & & & [208-210] & & & & & \\
\hline 1998 & [62] & [117] & & & & & & \\
\hline 2000 & [63] & & & & & & & \\
\hline 2001 & & & [206] & & & & & \\
\hline 2002 & {$[57,64]$} & {$[118,199]$} & [4] & & & & & \\
\hline 2003 & [59] & {$[164,200]$} & & & & & & \\
\hline 2004 & {$[25,26]$} & {$[125]$} & & & & & & \\
\hline 2005 & [56-69] & {$[127,129,133,134,165,201]$} & & & & & & \\
\hline 2006 & {$[6,70-73]$} & {$[119,126,135,136,139,166,167]$} & [215] & [227] & & {$[239,240]$} & & \\
\hline 2007 & {$[7,8,27,74,75,76]$} & {$[128,130,131,137,138,140,168,169]$} & [216] & & & [241] & & \\
\hline 2008 & {$[28,58,77]$} & {$[120,122,132,141,170]$} & & & & [242] & & \\
\hline 2009 & {$[78-81]$} & {$[121,123,124,147]$} & [217] & & & & & \\
\hline 2010 & [29-31] & & & & & [243] & & \\
\hline 2011 & {$[32,33,82,83,85]$} & [171] & {$[1,218]$} & [228-230] & [235] & [244] & & \\
\hline 2012 & {$[84,86-88]$} & {$[172-174,202]$} & [219] & [231] & & & & \\
\hline 2013 & {$[34-44,89-95]$} & {$[142,144-146,175-178,180-186]$} & {$[212,220]$} & [232] & & [245-247] & & \\
\hline 2014 & {$[45-50,96-109]$} & {$[143,148-162,179,187-194,203-205]$} & {$[211,221]$} & [233] & {$[236,237]$} & {$[248,249]$} & & \\
\hline 2015 & {$[51-54,110-114]$} & {$[163,180,195-198]$} & [213] & & & & & \\
\hline
\end{tabular}


Table 3. GAs applied to respective subject processes.

\begin{tabular}{lc}
\hline Processes & Genetic algorithm \\
\hline MFM & 93 \\
OF & 90 \\
DM & 16 \\
SRM & 07 \\
PDC & 03 \\
RM & 11 \\
CSM & 0 \\
CRM & 0 \\
Total & 220 \\
\hline
\end{tabular}

(Information Sciences), Industrial engineering (Industrial Management and Data Systems), Soft computing (Applied Soft Computing, Applied Mathematical Modelling, (Applied Mathematics and Computation), Mechanics and Materials (Applied Mechanics and Materials), Artificial Intelligence (Engineering Applications of Artificial Intelligence), Operations Management (International Journal of Physical Distribution \& Logistics Management), Manufacturing Technology (Journal of Manufacturing Technology Management.

- Types of GA variants used

Depending on the nature of the problem formulated, different variants of GA have been used. It is observed that in most of the papers a hybrid variant of GA is used, where hybridization is done with fuzzy logic, support vector machine, machine learning, local search methods, etc.; besides, GA has also been hybridized with other algorithms such as Tabu Search and SA. Since several SCM problems can be modeled as multi-objective optimization problems, multi-objective GA has been used for solving such cases. Parallel variants of GA have been used in two cases; while in some other cases, new operators are proposed or a study is done on the effect of change of parameters.

\section{- Future trend}

With the growing competition in today's environment, the mathematical models of SCM are becoming more and more
Table 4. Research articles published by main journals.

\begin{tabular}{lc}
\hline Journals title & $\begin{array}{c}\text { No. of } \\
\text { articles }\end{array}$ \\
\hline Expert Systems with Applications & 23 \\
Computers and Industrial engineering & 15 \\
International Journal of Production Research & 12 \\
European Journal of Operational Research & 10 \\
Journal of Intelligent Manufacturing & 12 \\
Computers \& Operations Research & 7 \\
International Journal of Production Economics & 7 \\
Journal of Advanced Manufacturing Technology & 6 \\
Information Sciences & 5 \\
Industrial Management and Data Systems & 3 \\
Applied Soft Computing & 3 \\
Applied Mathematical Modelling & 3 \\
Applied Mechanics and Materials & 3 \\
Engineering Applications of Artificial Intelligence & 3 \\
Applied Mathematics and Computation & 2 \\
International Journal of Physical Distribution \& & 2 \\
$\quad$ Logistics Management & \\
Journal of Manufacturing Technology & 2 \\
$\quad$ Management & \\
Others & 100 \\
\hline
\end{tabular}

complex. For example, in order to make the problem more realistic, problems are being formulated as multi-objective. This trend can be seen in the recent papers where the researchers have considered bi-objective or multi-objective models. Consequently, researchers are concentrating on developing multi-objective variants of GA. Secondly, the focus is also on developing efficient GAs for integer and mixed programming problems that may be linear or nonlinear.

\section{Summary}

Since its development in 1975, GAs have emerged as a powerful tool for dealing with problems arising in various fields. It is remarkable that despite the presence of several other soft computing techniques [252-255], GAs have maintained their

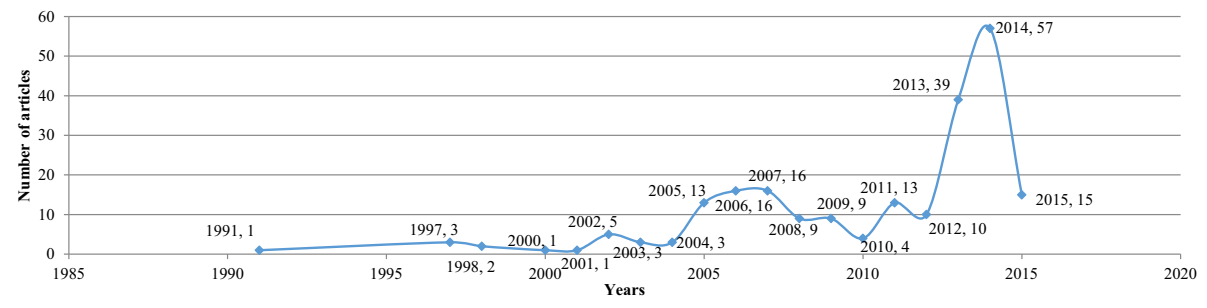

Figure 22. Number of articles in SCM using GA. 
own fan following and are widely used scientists and researchers in various fields [256-259]. GAs has particularly shown their efficiency in case of optimization models. This is one of the reasons why GAs has frequently been used for in SCM as many of the problems here can be formulated as optimization problems. The popularity of GA can also be attributed to the availability of fast computers and freely available GA tool boxes. The purpose of this paper is to familiarize the reader with the application of GA on the eight processes of SCM as given by Council of SCM Professionals (CSCMF), namely, Manufacturing flow management (MFM), which includes Inventory Management/Material Planning, Supply Chain Planning and Production Planning; Order fulfillment (OF), which has Logistics Network Design/Planning, Vehicle Routing/Assignment and Other issues as sub-processes; Demand management (DM) having Sales Forecasting and Bullwhip Effect as sub-processes; Supplier relationship management (SRM); Product development and commercialization (PDC); Returns management (RM); Customer service management (CSM); Customer relationship management (CRM). It is seen that in all the areas except CSM and CRM, GA has been applied successfully. The authors have tried to cover as many papers as possible; however, there is a possibility that some useful paper might have been overlooked.

\section{Acknowledgments}

We acknowledge DST, grant number INT/FRG/DAAD/P$251 / 2015$ for the partial financial support provided.

\section{References}

[1] Hadavandi E, Shavandia H and Ghanbarib A 2011 An improved sales forecasting approach by the integration of genetic fuzzy systems and data clustering: Case study of printed circuit board. Expert Syst. Appl. 38: 9392-9399

[2] Pal S K and Ghosh A 2004 Soft computing data mining. Inform. Sci. 163(1): 1-3

[3] Furuhashi T, Roy R, Chawdhry P 1999 Advances in soft computing: Engineering design and manufacturing. Berlin: Springer

[4] Jeong B, Junga H S and Parkb N K 2002 A computerized causal forecasting system using genetic algorithms in supply chain management. J. Syst. Softw. 60: 223-237

[5] Falkenauer E and Bouffouix S 1991 A genetic algorithm for job shop. In: Proceedings of IEEE International Conference on Robotics and Automation, 1991, pp. 824-829

[6] Chang P, Yao M, Huang S and Chen C 2006 A genetic algorithm for solving a fuzzy economic lot-size scheduling problem. Int. J. Prod. Econ. 102(2): 265-288

[7] Pourakbar M, Farahani R Z and Asgari N 2007 A joint economic lot-size model for an integrated supply network using genetic algorithm. Appl. Math. Comput. 189(1): 583-596

[8] Chi H, Ersoy O K, Moskowitz H and Ward J 2007 Modeling and optimizing a vendor managed replenishment system using machine learning and genetic algorithms. Eur. J. Oper. Res. 180(1): 174-193

[9] Jauhar S K and Pant M 2015 Genetic algorithms, a natureinspired tool: Review of applications in supply chain management. In: Proceedings of Fourth International Conference on Soft Computing for Problem Solving, pp. 71-86. India: Springer

[10] Holland J H 1992 Genetic algorithms. Sci. Am. 267(1): 66-72

[11] Forrest S 1996 Genetic algorithms. ACM Comput. Surv. (CSUR) 28(1): 77-80

[12] Grefenstette J J 1986 Optimization of control parameters for genetic algorithms. IEEE Trans. Syst. Man Cybern. 16(1): 122-128

[13] Mitchell M, Forrest S and Holland J H 1992 The royal road for genetic algorithms: Fitness landscapes and GA performance. In: F J Varela and P Bourgine (eds.) Toward a Practice of Autonomous Systems: Proceedings of the First European Conference on Artificial Life. Cambridge, MA: MIT Press/Bradford Books

[14] Koza J R 1990 Genetic programming: A paradigm for genetically breeding populations of computer programs to solve problems. Stanford University Computer Science Department technical report STAN-CS-90-1314

[15] Schaffer J D, Caruana R A, Eshelman L J and Das R 1989 A study of control parameters affecting online performance of genetic algorithms for function optimization. In: Proceedings of the Third International Conference on Genetic Algorithms, pp 51-60, Morgan Kaufmann Publishers Inc

[16] De Jong K 1990 Genetic algorithm based learning. In: Kondratoff Y, Michalski R S (eds.) Machine learning: An artificial intelligence approach. San Mateo, CA: Morgan Kaufmann

[17] Back T, Hammel U and Schwefel H P 1997 Evolutionary computation: Comments on the history and current state. IEEE Trans. Evolut. Comput. 1(1): 3-17

[18] Davis L (Ed) 1991 Handbook of genetic algorithms, vol. 115. New York: Van Nostrand Reinhold

[19] Jauhar S K and Pant M 2013 Recent trends in supply chain management: A soft computing approach. In: Proceedings of Seventh International Conference on Bio-Inspired Computing: Theories and Applications (BIC-TA 2012), pp. 465-478. India: Springer

[20] Christopher M (2005) Logistics and supply chain management: Creating value-adding networks. New York City: Pearson education

[21] Harrison A and Hoek R I 2005 Logistics management and strategy. New York City: Pearson Education

[22] Ko M, Tiwari A and Mehnen J A 2010 Review of soft computing applications in supply chain management. Appl. Soft Comput. 10: 661-674

[23] Douglas M, Lambert and Terrance L P 2001 Supply chain metrics. Int. J. Logist. Manag. 12(1): 1-19

[24] Verwijmeren M, Vlist P and Donselaar K 1996 Networked inventory management I formation systems: Materializing supply chain management. Int. J. Phys. Distrib. Logist. Manag. 26(6) 16-31

[25] Chan F T, Chung S H and Wadhwa S 2004 A heuristic methodology for order distribution in a demand driven collaborative supply chain. Int. J. Prod. Res. 42(1): 1-19 
[26] Chan F T and Chung S H 2004 A multi-criterion genetic algorithm for order distribution in a demand driven supply chain. Int. J. Comput. Integr. Manuf. 17(4): 339-351

[27] Nachiappan S P and Jawahar N 2007 A genetic algorithm for optimal operating parameters of VMI system in a two echelon supply chain. Eur. J. Oper. Res. 182(3): 1433-1452

[28] Wu M and Hsu Y 2008 Design of BOM configuration for reducing spare parts logistic costs. Expert Syst. Appl. 34(4): 2417-2423

[29] Pasandideh S H R, Niaki S T A and Yeganeh J A 2010 A parameter-tuned genetic algorithm for multi-product economic production quantity model with space constraint, discrete delivery orders and shortage. Adv. Eng. Softw. 41: 306-314

[30] Li M J, Chen D S, Cheng S Y, Wang F, Li Y, Zhou Y and Lang J L 2010 Optimizing emission inventory for chemical transport models by using genetic algorithm. Atmos. Env. 44: 3926-3934

[31] Lin K P, Chang P T, Hung K C and Pai P F 2010 A simulation of vendor managed inventory dynamics using fuzzy arithmetic operations with genetic algorithms. Expert Syst. Appl. 37: 2571-2579

[32] Pasandideh S H R, Niaki S T A and Nia A R 2011 A genetic algorithm for vendor managed inventory control system of multi-product multi-constraint economic order quantity model. Expert Syst. Appl. 38: 2708-2716

[33] Pasandideh S H R, Niaki S T A and Tokhmehchi N 2011 A parameter-tuned genetic algorithm to optimize two-echelon continuous review inventory systems. Expert Syst. Appl. 38: 11708-11714

[34] Taleizadeh A A and Cárdenas-Barrón L E 2013 Hybrid metaheuristics algorithms for inventory management problems. In: Meta-Heuristics Optimization Algorithms in Engineering, Business, Economics, and Finance, pp. 312-356. Hershey, PA: IGI Global

[35] Taleizadeh A A, Niaki S T A, Aryanezhad M B and Shafii N 2013 A hybrid method of fuzzy simulation and genetic algorithm to optimize constrained inventory control systems with stochastic replenishments and fuzzy demand. Inform. Sci. 220: 425-441

[36] Das D, Kar M B, Roy A and Kar S 2013 Two-warehouse production inventory model for a deteriorating item with time-varying demand and shortages: A genetic algorithm with varying population size approach. Optim. Eng. 1-19. doi:10.1007/s11081-013-9223-9

[37] Radhakrishnan P and Jayanthi N 2013 Application of genetic algorithm to supply chain inventory optimization. $J$. Contemp. Res. Manag. 5(1): 27-42. http://psgim.ac.in/jour nals/index.php/jcrm/article/view/92

[38] Sadok A, Teghem J and Chabcoub H 2013 Grouping genetic algorithms for a bi-objective inventory routing problem. Int. J. Multicrit. Decis. Mak. 3(2): 256-276

[39] Zhang H, Deng Y, Chan F T and Zhang X 2013 A modified multi-criterion optimization genetic algorithm for order distribution in collaborative supply chain. Appl. Math. Modell. 37(14): 7855-7864

[40] Sivakumar P, Ganesh K, Punnniyamoorthy M and Koh S C 2013 Genetic algorithm for inventory levels and routing structure optimization in two stage supply chain. Int. J. Inform. Syst. Supply Chain Manag. (IJISSCM) 6(2): 33-49
[41] Jana D K, Maity K, Das B and Roy T K 2013 A fuzzy simulation via contractive mapping genetic algorithm approach to an imprecise production inventory model under volume flexibility. J. Simul. 7(2): 90-100

[42] Pasandideh S H R, Niaki S T A and Far M H 2013 Optimization of vendor managed inventory of multiproduct EPQ model with multiple constraints using genetic algorithm. Int. J. Adv. Manuf. Technol. 1-12. doi:10.1007/ s00170-013-5476-x

[43] Cho D W, Lee Y H, Lee T Y and Gen M 2013 An adaptive genetic algorithm for the time dependent inventory routing problem. J. Intell. Manuf. 1-18. doi:10.1007/s10845-0120727-5

[44] Jana D K, Maity K and Roy T K 2013 Multi-objective imperfect production inventory model in fuzzy rough environment via genetic algorithm. Int. J. Oper. Res. 18(4): 365-385

[45] Saracoglu I, Topaloglu S and Keskinturk T 2014 A genetic algorithm approach for multi-product multi-period continuous review inventory models. Expert Syst. Appl. 41(18): 8189-8202

[46] Maiti A K, Maiti M K and Maiti M 2014 An EOQ model of an item with imprecise seasonal time via genetic algorithm. Int. J. Oper. Res. 19(3): 358-384

[47] Pasandideh S H R, Niaki S T A and Far M H 2014 Optimization of vendor managed inventory of multiproduct EPQ model with multiple constraints using genetic algorithm. Int. J. Adv. Manuf. Technol. 71(1-4): 365-376

[48] Jana D K, Maity K, Maiti M and Roy T K 2014 A multiobjective multi-item inventory control problem in fuzzyrough environment using soft computing techniques. Adv. Decis. Sci. 2014: 617989. doi:10.1155/2014/617989

[49] Diabat A 2014 Hybrid algorithm for a vendor managed inventory system in a two-echelon supply chain. Eur. J. Oper. Res. 238(1): 114-121

[50] Sadeghi J, Sadeghi S and Niaki S T A 2014 A hybrid vendor managed inventory and redundancy allocation optimization problem in supply chain management: An NSGA-II with tuned parameters. Comput. Oper. Res. 41: 53-64

[51] Nia A R, Far M H and Niaki S T A 2015 A hybrid genetic and imperialist competitive algorithm for green vendor managed inventory of multi-item multi-constraint EOQ model under shortage. Appl. Soft Comput. 30: 353-364

[52] Chan F T S, Tibrewal R K, Prakash A and Tiwari M K 2015 A biased random key genetic algorithm approach for inventory-based multi-item lot-sizing problem. Proc. Inst. Mech. Eng. B J. Eng. Manuf. 229(1): 157-171

[53] Sadeghi J and Niaki S T A 2015 Two parameter tuned multi-objective evolutionary algorithms for a bi-objective vendor managed inventory model with trapezoidal fuzzy demand. Appl. Soft Comput. 30: 567-576

[54] Arabzad S M, Ghorbani M and Tavakkoli-Moghaddam R 2015 An evolutionary algorithm for a new multi-objective location-inventory model in a distribution network with transportation modes and third-party logistics providers. Int. J. Prod. Res. 53(4): 1038-1050

[55] Braunscheidel M J and Suresh N C 2009 The organizational antecedents of a firm's supply chain agility for risk mitigation and response. J. Oper. Manag. 27: 119-140 
[56] Han C and Damrongwongsiri M 2005 Stochastic modeling of a two-echelon multiple sourcing supply chain system with genetic algorithm. J. Manuf. Technol. Manag. 16(1): 87-108

[57] Moon C, Kim J and Hur S 2002 Integrated process planning and scheduling with minimizing total tardiness in multiplants supply chain. Comput. Ind. Eng. 43(1-2):331-349

[58] Moon C, Lee Y H, Jeong C S and Yun Y 2008 Integrated process planning and scheduling in a supply chain. Comput. Ind. Eng. 54(4): 1048-1061

[59] Huin S F, Luong L H S and Abhary K 2003 Knowledgebased tool for planning of enterprise resources in ASEAN SMEs. Robot. Comput. Integr. Manuf. 19(5): 409-414

[60] Huang G Q, Zhang X Y and Liang L 2005 Towards integrated optimal configuration of platform products, manufacturing processes, and supply chains. J. Oper. Manag. 23(3-4) 267-290

[61] Nasab M K and Konstantaras I 2012 A random search heuristic for a multi-objective production planning. Comput. Ind. Eng. 62: 479-490

[62] Candido M A B, Khator S K and Barcia R M 1998 A genetic algorithm based procedure for more realistic job shop scheduling problems. Int. J. Prod. Res. 36(13): 3437-3457

[63] Maraghy H, Patel V and Abdallah IB 2000 Scheduling of manufacturing systems under dual-resource constraints using genetic algorithms. J. Manuf. Syst. 19(3): 186-201

[64] Xie J and Dong J 2002 Heuristic genetic algorithms for general capacitated lot-sizing problems. Comput. Math. Appl. 44 (1-2): 263-276

[65] Ossipov P 2005 Heuristic optimization of sequence of customer orders. Appl. Math. Comput. 162(3): 1303-1313

[66] Chan F T, Chung S H and Wadhwa S 2005 A hybrid genetic algorithm for production and distribution. Omega 33(4): 345-355

[67] Chan F T, Chung S H and Chan P L Y 2005 An adaptive genetic algorithm with dominated genes for distributed scheduling problems. Expert Syst. Appl. 29(2): 364-371

[68] Chan F T and Chung S H 2005 Multicriterion genetic optimization for due date assigned distribution network problems. Decis. Support Syst. 39(4): 661-675

[69] Chan F T S, Wong T C and Chan L Y 2005 A genetic algorithm-based approach to machine assignment problem. Int. J. Prod. Econ. Res. 43(12): 2451-2472

[70] Kampf M and Kochel P 2006 Simulation-based sequencing and lot size optimisation for a production-and-inventory system with multiple items. Int. J. Prod. Econ. 104(1): 191-200

[71] Chan F T S, Wong T C and Chan L Y 2006 Flexible jobshop scheduling problem under resource constraints. Int. J. Prod. Res. 44(11): 2071-2089

[72] Chan F T S, Chung S H and Chan P L Y 2006 Application of genetic algorithms with dominant genes in a distributed scheduling problem in flexible manufacturing systems. Int. J. Prod. Econ. Res. 44(3): 523-543

[73] Chan F T, Chung S H, Chan L Y, Finke G and Tiwari M K 2006 Solving distributed FMS scheduling problems subject to maintenance: Genetic algorithms approach. Robot. Comput. Integr. Manuf. 22(5): 493-504

[74] Bjork K and Carlsson C 2007 The effect of flexible lead times on a paper producer. Int. J. Prod. Econ. 107(1): $139-150$
[75] Chatfield D C 2007 The economic lot scheduling problem: A pure genetic search approach. Comput. Oper. Res. 34(10): 2865-2881

[76] Li Y, Chen J and Cai X 2007 Heuristic genetic algorithm for capacitated production planning problems with batch processing and remanufacturing. Int. J. Prod. Econ. 105(2): 301-317

[77] Chan F T S, Wong T C and Chan L Y 2008 Lot streaming for product assembly in job shop environment. Robot. Comput. Integr. Manuf. 24(3): 321-331

[78] Chung S H, Chan F T and Chan H K 2009 A modified genetic algorithm approach for scheduling of perfect maintenance in distributed production scheduling. Eng. Appl. Artif. Intell. 22(7): 1005-1014

[79] Chan F T, Wong T C and Chan L Y 2009 The application of genetic algorithms to lot streaming in a job-shop scheduling problem. Int. J. Prod. Res. 47(12): 3387-3412

[80] Chan F T and Kumar V 2009 Performance optimization of a leagility inspired supply chain model: A CFGTSA algorithm based approach. Int. J. Prod. Res. 47(3): 777-799

[81] Chan F T, Wong T C and Chan L Y 2009 An evolutionary algorithm for assembly job shop with part sharing. Comput. Ind. Eng. 57(3): 641-651

[82] Engin O, Ceran G, and Yilmaz M K 2011 An efficient genetic algorithm for hybrid flow shop scheduling with multiprocessor task problems. Appl. Soft Comput. 11: 3056-3065

[83] Ławrynowicz A 2011 Advanced scheduling with genetic algorithms in supply networks. J. Manuf. Technol. Manag. 22(6): 748-769

[84] Chiou C W, Chen W M, Liu C M and Wu M C 2012 A genetic algorithm for scheduling dual flow shops. Expert Syst. Appl. 39: 1306-1314

[85] Musharavati F and Hamouda A S M 2011 Modified genetic algorithms for manufacturing process planning in multiple parts manufacturing lines. Expert Syst. Appl. 38: 10770-10779

[86] Ramezanian R, Rahmani D and Barzinpour F 2012 An aggregate production planning model for two phase production systems: Solving with genetic algorithm and tabu search. Expert Syst. Appl. 39: 1256-1263

[87] Zamarripa M, Silvente J and Espuña A 2012 Supply chain planning under uncertainty using genetic algorithms. Comput. Aided Chem. Eng. 30: 457-461

[88] Wong C S, Chan F T S and Chung S H 2012 A genetic algorithm approach for production scheduling with mould maintenance consideration. Int. J. Prod. Res. 50(20): 5683-5697

[89] Vianna D S, Martins C B and Pulini I C 2013 Using multiobjective genetic algorithm and multicriteria analysis for the production scheduling of a Brazilian Garment Company. INTECH Open Access Publisher. doi:10.5772/53701

[90] Mok P Y, Cheung T Y, Wong W K, Leung S Y S and Fan J $\mathrm{T} 2013$ Intelligent production planning for complex garment manufacturing. J. Intell. Manuf. 24(1): 133-145

[91] Mahmudy W F, Marian R M and Luong L H 2013 Optimization of part type selection and loading problem with alternative production plans in flexible manufacturing system using hybrid genetic algorithms-part 1: Modelling and representation. In: 2013 5th International Conference on Knowledge and Smart Technology (KST), IEEE, pp. 75-80 
[92] Tan D D and Zhang Y M 2013 A method on process planning decision based on genetic algorithm. Adv. Mater. Res. 760: 1902-1905

[93] Chakrabortty R K and Hasin M A A 2013 Solving an aggregate production planning problem by fuzzy based genetic algorithm (FBGA) approach. Int. J. Fuzzy Logic Syst. (IJFLS) 3(1): 1-16

[94] Vasant P 2013 Hybrid linear search, genetic algorithms, and simulated annealing for fuzzy non-linear industrial production planning problems. In: Meta-Heuristics Optimization Algorithms in Engineering, Business, Economics, and Finance, pp. 87-109. Hershey, PA: IGI Global

[95] Chakrabortty R and Hasin M 2013 Solving an aggregate production planning problem by using multi-objective genetic algorithm (MOGA) approach. Int. J. Ind. Eng. Comput. 4(1): 1-12

[96] Babaei M, Mohammadi M and Ghomi S F 2014 A genetic algorithm for the simultaneous lot sizing and scheduling problem in capacitated flow shop with complex setups and backlogging. Int. J. Adv. Manuf. Technol. 70(1-4): 125-134

[97] Kim D and Shin H J 2014 A hybrid heuristic approach for production planning in supply chain networks. Int. J. Adv. Manuf. Technol. 1-12. doi:10.1007/s00170-014-6599-4

[98] Yan H S, Wan X Q and Xiong F L 2014 Integrated production planning and scheduling for a mixed batch job-shop based on alternant iterative genetic algorithm. J. Oper. Res. Soc. doi:10.1057/jors.2014.88

[99] Toledo C F M, de Oliveira L, de Freitas Pereira R, França P $\mathrm{M}$ and Morabito R 2014 A genetic algorithm/mathematical programming approach to solve a two-level soft drink production problem. Comput. Oper. Res. 48: 40-52

[100] Mohapatra P, Nayak A, Kumar S K and Tiwari M K 2014 Multi-objective process planning and scheduling using controlled elitist non-dominated sorting genetic algorithm. Int. J. Prod. Res. 1-24. doi:10.1080/00207543.2014.957872

[101] Zhang W, Gen M and Jo J 2014 Hybrid sampling strategybased multiobjective evolutionary algorithm for process planning and scheduling problem. J. Intell. Manuf. 25(5): 881-897

[102] GodinhoFilho M, Barco C F and Neto R F T 2014 Using genetic algorithms to solve scheduling problems on flexible manufacturing systems (FMS): A literature survey, classification and analysis. Flex. Serv. Manuf. J. 26(3): 408-431

[103] Slak A, Tavčar J and Duhovnik J 2014 Case study analysis and genetic algorithm adaptation for job process planning and scheduling in batch production. J. Des. Res. 12(1): $52-77$

[104] Cui L X 2014 Joint optimization of production planning and supplier selection incorporating customer flexibility: An improved genetic approach. J. Intell. Manuf. 1-19. doi:10.1007/s10845-014-0932-5

[105] Do Ngoc, A D, Lee S H and Moon I 2014 Hybrid genetic algorithm for test bed scheduling problems. Int. J. Prod. Res. 52(4): 1074-1089. doi:10.1080/00207543.2013. 838327

[106] Musharavati F and Hamouda A M S 2014 Multiple parts process planning in serial-parallel flexible flow lines: Part I-Process plan modeling framework. Int. J. Adv. Manuf. Technol. 1-23. doi:10.1007/s00170-014-6616-7

[107] Musharavati F and Hamouda A M S 2014 Multiple parts process planning in serial-parallel flexible flow lines: Part
II-Solution method based on genetic algorithms with fixed-and variable-length chromosomes. Int. J. Adv. Manuf. Technol. 1-39. doi:10.1007/s00170-014-6459-2

[108] Huang J and Süer G A 2014 A dispatching rule-based genetic algorithm for multi-objective job shop scheduling using fuzzy satisfaction levels. Comput. Ind. Eng. doi:10. 1016/j.cie.2014.12.001

[109] Chamnanlor C, Sethanan K, Chien C F and Gen M 2014 Re-entrant flow shop scheduling problem with time windows using hybrid genetic algorithm based on auto-tuning strategy. Int. J. Prod. Res. 52(9): 2612-2629

[110] İnkaya T and Akansel M 2015 Coordinated scheduling of the transfer lots in an assembly-type supply chain: A genetic algorithm approach. J. Intell. Manuf. 1-11. doi:10. 1007/s10845-015-1041-9

[111] Jamrus T, Chien C F, Gen M and Sethanan K 2015 Multistage production distribution under uncertain demands with integrated discrete particle swarm optimization and extended priority-based hybrid genetic algorithm. Fuzzy Optim. Decis. Mak. 14(3): 265-287

[112] Furlan M, Almada-Lobo B, Santos M and Morabito R 2015 Unequal individual genetic algorithm with intelligent diversification for the lot-scheduling problem in integrated mills using multiple-paper machines. Comput. Oper. Res. 59: 33-50

[113] Zhang L and Wong T N 2015 An object-coding genetic algorithm for integrated process planning and scheduling. Eur. J. Oper. Res. 244(2): 434-444

[114] Costa A, Cappadonna F A and Fichera S 2015 A hybrid genetic algorithm for minimizing makespan in a flow-shop sequence-dependent group scheduling problem. J. Intell. Manuf. 1-15. doi:10.1007/s10845-015-1049-1

[115] Kritchanchai D and MacCarthy B L 1999 Responsiveness of the order fulfilment process. Int. J. Oper. Prod. Manag. 19(8): 812-833

[116] Shu J, Li Z, Shen H, Wuc T, Zhong 2012 W A logistics network design model with vendor managed inventory. Int. J. Prod. Econom. 135: 754-761

[117] Berry L M, Murtagh B A, McMahon G B, Sugden S J and Welling L D 1998 Genetic algorithms in the design of complex distribution networks. Int. J. Phys. Distrib. Logist. Manag. 28(5): 377

[118] Syarif A, Yun Y and Gen M 2002 Study on multi-stage logistic chain network: A spanning tree-based genetic algorithm approach. Comput. Ind. Eng. 43(1-2): 299-314

[119] Xu H, Xu R and Ye Q 2006 Optimization of unbalanced multistage logistics systems based on prüfer number and effective capacity coding. Tsinghua Sci. Technol. 11(1): 96-101

[120] Xu J, Liu Q and Wang R 2008 A class of multi-objective supply chain networks optimal model under random fuzzy environment and its application to the industry of Chinese liquor. Inform. Sci. 178(8): 2022-2043

[121] Xu T, Wei H and Wang Z 2009 Study on continuous network design problem using simulated annealing and genetic algorithm. Expert Syst. Appl. 36(2): 1322-1328

[122] Farahani R Z and Elahipanah M 2008 A genetic algorithm to optimize the total cost and service level for just-in-time distribution in a supply chain. Int. J. Prod. Econ. 111(2): 229-243

[123] Altiparmak F, Gen M, Lin L and Karaoglan I 2009 A steady-state genetic algorithm for multi-product supply chain network design. Comput. Ind. Eng. 56(2): 521-537 
[124] Jawahar N and Balaji A N 2009 A genetic algorithm for the two-stage supply chain distribution problem associated with a fixed charge. Eur. J. Oper. Res. 194(2): 496-537

[125] Chan F T S and Chung S H 2004 Multi-criteria genetic optimization for distribution network problems. Int. J. Adv. Manuf. Technol. 24(7-8): 517-532

[126] Chan F T, Chung S H and Choy K L 2006 Optimization of order fulfillment in distribution network problems. J. Intell. Manuf. 17(3): 307-319

[127] Ma H and Davidrajuh R 2005 An iterative approach for distribution chain design in agile virtual environment. Ind. Manag. Data Syst. 105(6): 815-834

[128] Jo J, Li Y and Gen M 2007 Nonlinear fixed charge transportation problem by spanning tree-based genetic algorithm. Comput. Ind. Eng. 53(2): 290-298

[129] Gen M and Syarif A 2005 Hybrid genetic algorithm for multi-time period production/distribution planning. Comput. Ind. Eng. 48(4): 799-809

[130] Aliev R A, Fazlollahi B, Guirimov B G and Aliev R R 2007 Fuzzy-genetic approach to aggregate production-distribution planning in supply chain management. Inform. Sci. 177(20): 4241-4255

[131] Silva C A, Sousa J M C and Runkler T A 2007 Optimization of logistic systems using fuzzy weighted aggregation. Fuzzy Sets Syst. 158(17): 1947-1960

[132] Silva C A, Sousa J M C and Runkler T A 2008 Rescheduling and optimization of logistic processes using GA and ACO. Eng. Appl. Artif. Intell. 21(3): 343-352

[133] Fischer T and Gehring H 2005 Planning vehicle transhipment in a seaport automobile terminal using a multi-agent system. Eur. J. Oper. Res. 166(3): 726-740

[134] Lau H C W, Ning A, Pun K F, Chin K S and Ip W H 2005 A knowledge-based system to support procurement decision. J. Knowl. Manag. 9(1): 87-100

[135] Altiparmak F, Gen M, Lin L and Paksoy T 2006 A genetic algorithm approach for multiobjective optimization of supply chain networks. Comput. Ind. Eng. 51(1): 196-215

[136] Caputo A C, Fratocchi L and Pelagagge P M 2006 A genetic approach for freight transportation planning. Ind. Manag. Data Syst. 106(5): 719-738

[137] Shintani K, Imai A, Nishimura E and Papadimitriou S 2007 The container shipping network design problem with empty container repositioning. Transp. Res. E Logist. Transp. Rev. 43(1): 39-59

[138] Naso D, Surico M, Turchiano B and Kaymak U 2007 Genetic algorithms for supply-chain scheduling: A case study in the distribution of ready-mixed concrete. Eur. J. Oper. Res. 177(3): 2069-2099

[139] Ko H J, Ko C S and Kim T 2006 A hybrid optimization/ simulation approach for a distribution network design of 3PLS. Comput. Ind. Eng. 50(4): 440-449

[140] Ko H J and Evans G W 2007 A genetic algorithm-based heuristic for the dynamic integrated forward/reverse logistics network for 3PLs. Comput. Oper. Res. 34(2): 346-366

[141] Lam C Y, Chan S L, Ip W H and Lau C W 2008 Collaborative supply chain network using embedded genetic algorithms. Ind. Manag. Data Syst. 108(8): 1101-1110

[142] Li L H, Fu Z, Zhou H P and Hu Z D 2013 Discrete logistics network design model under interval hierarchical OD demand based on interval genetic algorithm. J. Central South Univ. 20: 2625-2634
[143] Cheng J, Du P and Zhao M 2014 The research on continuous equilibrium network design model of stochastic demand and supply based on genetic algorithm. Bridges. doi:10.1061/9780784412602.0047

[144] Hiremath N C, Sahu S and Tiwari M K 2013 Multi objective outbound logistics network design for a manufacturing supply chain. J. Intell. Manuf. 24(6): 1071-1084

[145] Cheshmehgaz H R, Desa M I and Wibowo A 2013 A flexible three-level logistic network design considering cost and time criteria with a multi-objective evolutionary algorithm. J. Intell. Manuf. 24(2): 277-293

[146] Roghanian E and Kamandanipour K 2013 A fuzzy-random programming for integrated closed-loop logistics network design by using priority-based genetic algorithm. Int. J. Ind. Eng. Comput. 4(1): 139-154

[147] Lau H C, Chan T M, Tsui W T, Chan F T, Ho G T and Choy K L 2009 A fuzzy guided multi-objective evolutionary algorithm model for solving transportation problem. Expert Syst. Appl. 36(4): 8255-8268

[148] Lin L, Zhang X, Yuan X and Zhou H 2014 Research on supply chain distribution network of bi-level programming model based on two-way approximation genetic algorithm. In: WHICEB Proceedings, p. 85

[149] Soleimani H and Kannan G 2015 A hybrid particle swarm optimization and genetic algorithm for closed-loop supply chain network design in large-scale networks. Appl. Math. Modell. 39(14): 3990-4012. doi:10.1016/j.apm.2014.12.016

[150] Demirel N, Özceylan E, Paksoy T and Gökçen H 2014 A genetic algorithm approach for optimising a closed-loop supply chain network with crisp and fuzzy objectives. Int. J. Prod. Res. 52(12): 3637-3664

[151] Che Z H, Chiang T A, Kuo Y C and Cui Z 2014 Hybrid algorithms for fuzzy reverse supply chain network design. Sci. World J. 2014: 497109. doi:10.1155/2014/497109

[152] Gu C and Tao Q 2014 A transforming quantum-inspired genetic algorithm for optimization of green agricultural products supply chain network. In: Computer engineering and networking, pp. 145-152. Springer International Publishing. doi:10.1007/978-3-319-01766-2_17

[153] Ghasimi S A, Ramli R and Saibani N 2014 A genetic algorithm for optimizing defective goods supply chain costs using JIT logistics and each-cycle lengths. Appl. Math. Modell. 38(4): 1534-1547

[154] Taha R, Abdallah K, Sadek Y, El-Kharbotly A and Afia N 2014 Design of supply chain networks with supply disruptions using genetic algorithm. In: 25th annual POMS conference proceedings. Retrieved from https://mpra.ub. uni-muenchen.de/id/eprint/58062

[155] Dzupire N C and Nkansah-Gyekye Y 2014 A multi-stage supply chain network optimization using genetic algorithms. http://arxiv.org/abs/arXiv:1408.0614

[156] Rajendran V, Devadasan S R and Kannan S 2014Design of a logistics network in an organisation for optimising logistics cost and inventory using RSM and genetic algorithm. Appl. Mech. Mater. 592: 2601-2607

[157] Roghanian E and Pazhoheshfar P 2014 An optimization model for reverse logistics network under stochastic environment by using genetic algorithm. J. Manuf. Syst. 33(3): 348-356

[158] Chang F S, Wu J S, Lee C N and Shen H C 2014 Greedysearch-based multi-objective genetic algorithm for 
emergency logistics scheduling. Expert Syst. Appl. 41(6): 2947-2956

[159] Sadrnia A, Ismail N, Ariffin M K A M, Norzima Z and Boyer O 2014 Reverse logistics network optimizing by genetic algorithm: A case study of automotive wiring harnesses. Appl. Mech. Mater. 564: 740-746

[160] Liu D 2014 Network site optimization of reverse logistics for E-commerce based on genetic algorithm. Neur. Comput. Appl. 25(1): 67-71

[161] Chen J 2014 Logistics network optimization of import crude oil in china based on genetic algorithm. Adv. Mater. Res. 945: 3126-3129

[162] Hernandez-Hernandez H J, Montoya-Torres J R and Niebles-Atencio F 2014 Design of multi-product/multi-period closed-loop reverse logistics network using a genetic algorithm. In: 2014 IEEE Symposium on Computational Intelligence in Production and Logistics Systems (CIPLS), pp. $40-47$

[163] Pasandideh S H R, Niaki S T A and Asadi K 2015 Biobjective optimization of a multi-product multi-period three-echelon supply chain problem under uncertain environments: NSGA-II and NRGA. Inform. Sci. 292: 57-74

[164] Baker B M and Ayechew M A 2003 A genetic algorithm for the vehicle routing problem. Comput. Oper. Res. 30: 787-800

[165] Pankratz G 2005 Dynamic vehicle routing by means of a genetic algorithm. Int. J. Phys. Distrib. Logist. Manag. 35(5): 362-383

[166] Torabi S A, Ghomi S M T F and Karimi B 2006 A hybrid genetic algorithm for the finite horizon economic lot and delivery scheduling in supply chains. Eur. J. Oper. Res. 173(1): 173-189

[167] Fu L, Sun D and Rilett L R 2006 Heuristic shortest path algorithms for transportation applications: State of the art. Comput. Oper. Res. 33(11): 3324-3343

[168] Yang V, Ji X, Gao Z and Li K 2007 Logistics distribution centers location problem and algorithm under fuzzy environment. J. Comput. Appl. Math. 208(2): 303-315

[169] Ganesh K and Narendran T T 2007 CLOVES: A clusterand-search heuristic to solve the vehicle routing problem with delivery and pick-up. Eur. J. Oper. Res. 178(3): 699-717

[170] Ho W, Ho G T S, Ji P and Lau H C W 2008 A hybrid genetic algorithm for the multi-depot vehicle routing problem. Eng. Appl. Artif. Intell. 21(4): 548-557

[171] Yucenur G N and Demirel N C 2011 A new geometric shape-based genetic clustering algorithm for the multi-depot vehicle routing problem. Expert Syst. Appl. 38: 11859-11865

[172] Anbuudayasankar S P, Ganesh K, Koh S C L and Ducq Y 2012 Modified savings heuristics and genetic algorithm for bi-objective vehicle routing problem with forced backhauls. Expert Syst. Appl. 39 2296-2305

[173] Chung-Cheng L and Vincent F Y 2012 Data envelopment analysis for evaluating the efficiency of genetic algorithms on solving the vehicle routing problem with soft time windows. Comput. Ind. Eng. 63: 520-529

[174] Derbel H, Jarboui B, Hanafi S and Chabchoub H 2012 Genetic algorithm with iterated local search for solving a location-routing problem. Expert Syst. Appl. 39: 2865-2871
[175] Vidal T, Crainic T G, Gendreau M and Prins C 2013 A hybrid genetic algorithm with adaptive diversity management for a large class of vehicle routing problems with time-windows. Comput. Oper. Res. 40(1): 475-489

[176] Lu T, Zhan T and Hu F 2013 Application of niche cellular genetic algorithm in vehicle routing problem with time windows. In: International Asia Conference on Industrial Engineering and Management Innovation (IEMI2012) Proceedings, pp. 405-415. Berlin: Springer

[177] Osaba E, Carballedo R, Diaz F and Perallos A 2013 Discussion related to "Wang C-H. and Lu, J.-Z. 2009 A hybrid genetic algorithm that optimizes capacitated vehicle routing problem. Expert Syst. Appl., 36(2), 2921-2936". Expert Syst. Appl., 40(14): 5425-5426

[178] Deng Y, Xiang J and Ou Z 2013 Improvement of genetic algorithm for vehicle routing problems with time windows. In: 2013 IEEE Third International Conference on Intelligent System Design and Engineering Applications (ISDEA), pp. 866-869

[179] Hsu L F, Hsu C C and Lin T D 2014 An intelligent artificial system: Artificial immune based hybrid genetic algorithm for the vehicle routing problem. Appl. Math. 8(3): 1191-1200

[180] Barkaoui M and Gendreau M 2013 An adaptive evolutionary approach for real-time vehicle routing and dispatching. Comput. Oper. Res. 40(7): 1766-1776

[181] Ventresca M, Ombuki-Berman B and Runka A 2013 Predicting genetic algorithm performance on the vehicle routing problem using information theoretic landscape measures. In: Evolutionary computation in combinatorial optimization pp. 214-225. Berlin: Springer

[182] Huang S, Fu X, Chen P, Ge C and Teng S 2013 An application study on vehicle routing problem based on improved genetic algorithm. In: Pervasive computing and the networked world, pp. 246-258. Berlin: Springer

[183] Liu R, Jiang Z and Geng N 2013 Erratum to: A hybrid genetic algorithm for the multi-depot open vehicle routing problem. OR Spectrum 1-2. doi:10.1007/s00291-013-03463

[184] Ursani Z, Essam D, Cornforth D and Stocker R 2013 Enhancements to the localized genetic algorithm for large scale capacitated vehicle routing problems. Int. J. Appl. Evol. Comput. (IJAEC) 4(1): 17-38

[185] Jie Jian, Xu Wang and Xianlong G E 2013 Research on capacitated vehicle routing problem with cloud adaptive genetic algorithm. J. Chongqing Univ. 8: 006

[186] Zhou W, Song T, He F and Liu X 2013 Multiobjective vehicle routing problem with route balance based on genetic algorithm. Discrete Dyn. Nature Soc. 2013: 325686. doi:10.1155/2013/325686

[187] Elhassania M, Jaouad B and Ahmed E A 2014 Solving the dynamic vehicle routing problem using genetic algorithms. In: 2014 IEEE International Conference on Logistics and Operations Management (GOL), pp. 62-69

[188] Nguyen P K, Crainic T G and Toulouse M 2014 A hybrid generational genetic algorithm for the periodic vehicle routing problem with time windows. J. Heuristics 20(4): $383-416$

[189] Sivaram Kumar V, Thansekhar M R and Saravanan R 2014 A new multi objective genetic algorithm: Fitness 
aggregated genetic algorithm (FAGA) for vehicle routing problem. Adv. Mater. Res. 984: 1261-1268

[190] Liu R, Jiang Z and Geng N 2014 A hybrid genetic algorithm for the multi-depot open vehicle routing problem. $O R$ Spectrum 36(2): 401-421

[191] Pierre D M and Zakaria N 2014 Partially optimized cyclic shift crossover for multi-objective genetic algorithms for the multi-objective vehicle routing problem with timewindows. In: 2014 IEEE Symposium on Computational Intelligence in Multi-Criteria Decision-Making (MCDM), pp. 106-115

[192] Mohr C M 2014 Optimization of warehouse order-picking routes using vehicle routing model and genetic algorithm. Doctoral dissertation, State University of New York at Binghamton

[193] Kumar V S, Thansekhar M R, Saravanan R and Amali S M J 2014 Solving multi-objective vehicle routing problem with time windows by FAGA. Proc. Eng. 97: 2176-2185

[194] Zhang J and Li J 2014 A hybrid genetic algorithm to the vehicle routing problem with fuzzy cost coefficients. In: 2014 IEEE 11th International Conference on Fuzzy Systems and Knowledge Discovery (FSKD), pp. 147-152

[195] Psychas I D, Marinaki M and Marinakis Y 2015 A parallel multi-start NSGA II algorithm for multiobjective energy reduction vehicle routing problem. In: International Conference on Evolutionary Multi-Criterion Optimization, pp. 336-350. Springer International Publishing. doi:10. 1007/978-3-319-15934-8_23

[196] Cai Y G, Tang Y L and Yang Q J 2015 An improved genetic algorithm for multi-depot heterogeneous vehicle routing problem with simultaneous pickup and delivery time windows. Appl. Mech. Mater. 738: 361-365

[197] Karakatič S and Podgorelec V 2015 A survey of genetic algorithms for solving multi depot vehicle routing problem. Appl. Soft Comput. 27: 519-532

[198] Ahmadizar F, Zeynivand M and Arkat J 2015 Two-level vehicle routing with cross-docking in a three-echelon supply chain: A genetic algorithm approach. Appl. Math. Model. 39(22): 7065-7081

[199] Zhou G, Min H and Gen M 2002 The balanced allocation of customers to multiple distribution centers in the supply chain network: A genetic algorithm approach. Comput. Ind. Eng. 43(1-2): 251-261

[200] Zhou G, Min H and Gen M 2003 A genetic algorithm approach to the bi-criteria allocation of customers to warehouses. Int. J. Prod. Econ. 86(1): 35-45

[201] Dullaert W, Maes B, Vernimmen B and Witlox F 2005 An evolutionary algorithm for order splitting with multiple transport alternatives. Expert Syst. Appl. 28(2): 201-208

[202] Yang W, Chan F T and Kumar V 2012 Optimizing replenishment polices using genetic algorithm for singlewarehouse multi-retailer system. Expert Syst. Appl. 39(3): 3081-3086

[203] Wang B, Fu X, Chen T and Zhou G 2014 Modeling supply chain facility location problem and its solution using a genetic algorithm. J. Softw. 9(9): 2335-2341

[204] Nearchou A C, Giannikos I C and Lagodimos A G 2014 A genetic algorithm for the economic manpower shift planning problem. Cybern. Syst. 45(5): 439-464
[205] Rahmani A and MirHassani S A 2014 A hybrid FireflyGenetic Algorithm for the capacitated facility location problem. Inform. Sci. 283, 70-78

[206] Kuo R J 2001 A sales forecasting system based on fuzzy neural network with initial weights generated by genetic algorithm. Eur. J. Oper. Res. 129(3): 496-517

[207] Lawrence J A and Pasternack B A 2002 Applied management science: Modelling, spreadsheet analysis, and communication for decision making, 2nd ed. New Jersey: Wiley

[208] Chiraphadhanakul S, Dangprasert P and Avatchanakorn V 1997 Genetic algorithms in forecasting commercial banks deposit. In: Proceeding of IEEE International Conference on Intelligent Processing Systems, vol. 1, pp. 557-565

[209] Ju Y K, Kim C and Shim J C 1997 Genetic based fuzzy models: Interest rate forecasting problem. Comput. Ind. Eng. 33: 561-564

[210] Kim D and Kim C 1997 Forecasting time series with genetic fuzzy predictor ensemble. IEEE Trans. Fuzzy Syst. 5: 523-535

[211] Zhang S and Qinghe H 2014 Application of GA optimizing neural network to coal sales forecasts. In: 2nd International Conference on Information, Electronics and Computer. Atlantis Press

[212] Gao L, Xu K L and Mao D X 2013 Research of sales forecasting model and algorithm in food and beverage enterprise. In: The 19th International Conference on Industrial Engineering and Engineering Management, pp. 925-934. Berlin: Springer

[213] Jun T and Qing W 2015 Optimize BP neural network structure on car sales forecasts based on genetic algorithm. In: International Industrial Informatics and Computer Engineering Conference (IIICEC 2015), pp. 75-79. Atlantis Press

[214] Kristianto Y, Helo P, Jiao J and Sandhu M 2012 Adaptive fuzzy vendor managed inventory control for mitigating the Bullwhip effect in supply chains. Eur. J. Oper. Res. 216: 346-355

[215] O'donnell T, Maguire L, McIvor R and Humphreys P 2006 Minimizing the bullwhip effect in a supply chain using genetic algorithms. Int. J. Prod. Res. 44(8): 1523-1543

[216] Lu J, Humphreys P, McIvor R and Maguire L 2007 Employing genetic algorithms to minimise the bullwhip effect in a supply chain. In: 2007 IEEE International Conference on Industrial Engineering and Engineering Management, pp. 1527-1531

[217] Lu J, Humphreys P, McIvor R and Maguire L 2009 Employing Genetic Algorithms to minimise the Bullwhip Effect in an online efficient-responsive supply chain. In: SOLI'09. IEEE/INFORMS International Conference on Service Operations, Logistics and Informatics, 2009. pp. $117-122$

[218] Othman K A and Gomma H W 2011, Reducing the bullwhip effect in supply chains using genetic algorithm and control engineering. In: 2011 IEEE International Conference on Systems, Man, and Cybernetics (SMC), pp. 440-445

[219] Yesmin T and Hasin M A A 2012 Determination of optimal ordering quantity and reduction of bullwhip effect in a multistage supply chain using genetic algorithm. Int. J. Integr. Supply Manag. 7(4): 193-214 
[220] Tosun U, Dokeroglu T and Cosar A 2013A new parallel genetic algorithm for reducing the bullwhip effect in an automotive supply chain. Manuf. Modell. Manag. Control 7(1): 70-74

[221] Devika K, Jafarian A, Hassanzadeh A and Khodaverdi R 2014 Optimizing of bullwhip effect and net stock amplification in three-echelon supply chains using evolutionary multi-objective metaheuristics. Ann. Oper. Res. 1-31. doi:10.1007/s10479-013-1517-y

[222] Herrmann J and Hodgson B 2001 SRM: Leveraging the supply base for competitive advantage In: Proceedings of the SMTA International Conference, Chicago, Illinois, 1 October, 2001

[223] Jauhar S K, Pant M and Deep A 2013 An approach to solve multi-criteria supplier selection while considering environmental aspects using differential evolution. In: International conference on swarm, evolutionary, and memetic computing, pp. 199-208. Springer International Publishing. doi:10.1007/978-3-319-03753-0_19

[224] Jauhar S, Pant M and Deep A 2014 Differential evolution for supplier selection problem: A DEA based approach. In: Proceedings of the Third International Conference on Soft Computing for Problem Solving, pp. 343-353. India: Springer

[225] Jauhar S K, Pant M and Abraham A 2014 A novel approach for sustainable supplier selection using differential evolution: A case on pulp and paper industry. In: Intelligent data analysis and its applications, vol. 2, pp. 105-117. Springer International Publishing. doi:10.1007/978-3-319-07773-4_11

[226] Kumar Jauhar S, Pant M and Nagar M C 2015 Differential evolution for sustainable supplier selection in pulp and paper industry: a DEA based approach. Comp Methods Mater. Sci. 15(1): 118-126. Retrieved from http://yadda. icm.edu.pl/baztech/element/bwmeta1.element.baztech9d8e4f95-3ff8-4093-9841-2bf874d49ed4

[227] Chiadamrong N and Prasertwattana K 2006 A comparative study of supply chain models under the traditional centralized and coordinating policies with incentive schemes. Comput. Ind. Eng. 50(4): 367-384

[228] Yang P C, Wee H M, Pai S and Tseng Y F 2011 Solving a stochastic demand multi-product supplier selection model with service level and budget constraints using Genetic Algorithm. Expert Syst. Appl. 38: 14773-14777

[229] Yeh W C and Chuang M C 2011 Using multi-objective genetic algorithm for partner selection in green supply chain problems. Expert Syst. Appl. 38: 4244-4253

[230] Yang P C, Wee H M, Pai S and Tseng Y F 2011 Solving a stochastic demand multi-product supplier selection model with service level and budget constraints using Genetic Algorithm. Expert Syst. Appl. 38(12): 14773-14777

[231] Sadeghieh A, Dehghanbaghi M, Dabbaghi A and Barak S 2012 A genetic algorithm based grey goal programming (G3) approach for parts supplier evaluation and selection. Int. J. Prod. Res. 50(16): 4612-4630

[232] Shen Y S, Yang C C, Chung C J and Lin S C 2013 A multiple-supplier-multiple-buyer collaborative supply chain model considering information sharing investment using genetic algorithm solutions. Int. Rev. Bus. Res. Pap. 9(3): 146-161

[233] Chan G Y and Khoh C T 2014 Enhancing decision of supplier selection using a genetic algorithm: A case study.
In: 2014 10th International Conference on Natural Computation (ICNC), pp. 315-320

[234] Cooper Robert G, Edgett S J and Kleinschmidt E J 1998 Portfolio management for new products, Reading, MA; Perseus Books

[235] Fernando M L and Escobedo P 2011 Selecting the best portfolio alternative from a hybrid multiobjective GAMCDM approach for new product development in the pharmaceutical industry. In: 2011 IEEE Symposium on Computational Intelligence in Multicriteria DecisionMaking (MDCM), pp. 159-166

[236] Bao B, Yang Y, Liu A, Zhao J and Li L 2014 Task allocation optimization in collaborative customized product development based on adaptive genetic algorithm. J. Intell. Syst. 23(1): 1-19

[237] Fung C K, Kwong C K, Chan K Y and Jiang H 2014 A guided search genetic algorithm using mined rules for optimal affective product design. Eng. Optim. 46(8): 1094-1108

[238] Rogers D S, Lambert D M, Croxton K L and García-Dastugue S J 2002 The returns management process. Int. J. Logist. Manag. 13(2): 1-18

[239] Min H, Ko C S and Ko H J 2006 The spatial and temporal consolidation of returned products in a closed-loop supply chain network. Comput. Ind. Eng. 51(2): 309-320

[240] Min H, Jeongko H and SeongKo C 2006 A genetic algorithm approach to developing the multiechelon reverse logistics network for product returns. Omega Int. J. Manag. Sci. 34(1) 56-69

[241] Lieckens K and Vandaele N 2007 Reverse logistics network design with stochastic lead times. Comput. Oper. Res. 34(2): 395-416

[242] Min H and Ko H 2008 The dynamic design of a reverse logistics network from the perspective of third-party logistics service providers. Int. J. Prod. Econ. 113(1): 176-192

[243] Trappey A J, Trappey C V and Wu C R 2010 Genetic algorithm dynamic performance evaluation for RFID reverse logistic management. Expert Syst. Appl. 37(11): 7329-7335

[244] Zhou G and Min H 2011 Designing a closed-loop supply chain with stochastic product returns: A Genetic Algorithm approach. Int. J. Logist. Syst. Manag. 9(4): 397-418

[245] Diabat A, Kannan D, Kaliyan M and Svetinovic D 2013 An optimization model for product returns using genetic algorithms and artificial immune system. Res. Conserv. Recycl. 74: 156-169

[246] Li Y, Guo H, Wang L and Fu J 2013 A hybrid geneticsimulated annealing algorithm for the location-inventoryrouting problem considering returns under E-supply chain environment. Sci. World J. 2013: 125893. doi:10.1155/ 2013/125893

[247] Boudhar H, Dahane M and Rezg N 2013 Spare part returns in stochastic deteriorating manufacturing system under a condition-based maintenance policy: Simulation-based genetic algorithm approach. Manuf. Modell. Manag. Control 7(1): 1399-1404

[248] Guo H and Li Y 2014 Multiobjective location-inventoryrouting problem taking returns into consideration. In: Proceedings of the Ninth International Symposium on Linear Drives for Industry Applications, vol 2, pp. 19-26. Berlin: Springer 
[249] Ghezavati V and Nia N S 2014 Development of an optimization model for product returns using genetic algorithms and simulated annealing. Soft Comput. 1-15. doi:10. 1007/s00500-014-1465-8

[250] Langer M, Loidl S and Nerb M 1999 Customer service management: Towards a management information base for an IP connectivity service. In: The Fourth IEEE Symposium on Computers and Communications, Red Sea, Egypt, pp. 149-155

[251] Robert S 1991 Computer aided marketing and selling. In: Butterworth Heinemann ISBN 978-0-7506-1707-9

[252] Jauhar S K and Pant M 2016 Sustainable supplier's management using differential evolution. In: Problem solving and uncertainty modeling through optimization and soft computing applications, pp. 239-263. Hershey, PA: Information Science Reference. doi:10.4018/978-1-4666-98857.ch012

[253] Enireddy V and Kumar R K 2015 Improved cuckoo search with particle swarm optimization for classification of compressed images. Sadhana 40(8): 2271-2285

[254] Jauhar S K and Pant M 2016 Using differential evolution to develop a carbon integrated model for performance evaluation and selection of sustainable suppliers in Indian automobile supply chain. In: Proceedings of Fifth International
Conference on Soft Computing for Problem Solving. Springer International Publishing

[255] Garg S, Patra K and Pal S K 2014 Particle swarm optimization of a neural network model in a machining process. Sadhana 39(3): 533-548

[256] Jauhar S K and Pant M 2016 Sustainable supplier selection: a new differential evolution strategy with automotive industry application. In: Recent developments and new direction in soft-computing foundations and applications, pp. 353-371. Springer International Publishing. doi:10. 1007/978-3-319-32229-2_25

[257] Balachandar C, Arunkumar S and Venkateasan M 2015 Computational heat transfer analysis and combined ANNGA optimization of hollow cylindrical pin fin on a vertical base plate. Sadhana 40(6): 1845-1863

[258] Jauhar S K, Pant M and Dutt R 2016 Performance measurement of an Indian higher education institute: A sustainable educational supply chain management perspective. Int. J. Syst. Assur. Eng. Manag. 1-14. doi:10.1007/s13198016-0505-4

[259] Jeevananthan S 2015 Influence of crossover methods used by genetic algorithm-based heuristic to solve the selective harmonic equations (SHE) in multi-level voltage source inverter. Sadhana 40(8): 2389-2410 